\title{
Long-Period $P$ Waveforms and the Source Mechanism of Intermediate Earthquakes
}

\author{
By \\ Takeshi Mrкumo \\ Disaster Prevention Research Institute, Kyoto University
}

\begin{abstract}
Long-period $P$ waveforms have been analyzed to interpret the source mechanism of four intermediate earthquakes with magnitudes of $6.0 \sim 6.5$ and focal depths between 100 and $200 \mathrm{~km}$.

The synthetic seismograms appropriate to each recording station have been constructed, to compare with observed records, on the basis of moving dislocation models with various parameters, including the fault length and width, the amount of dislocation, its time dependence and the fracture velocity, taking into account the combined effects of wave propagation in the earth and of a recording instrument. General features of the observed waveforms do not differ greatly from those for a double-couple point source, but the comparison with synthesized waveforms at a number of stations indicated seismic moment of order of $5 \sim 9 \times 10^{26}$ dyne $\cdot \mathrm{cm}$, and also probable ranges for some other source parameters on the assumed source. The bounds of the stress-strain drop, the released strain energy, and of efficiency of seismic wave radiation at the source were also discussed.
\end{abstract}

\section{§1. Introduction}

It appears that new evidence has now been provided by recent seismic and geodetic observations made at the near and far fields that the mechanism of energy release in many large shallow earthquakes can be explained by faulting or shear dislocations. Seismological approaches thus far made have been limited to determine the fault plane orientation from the first motion of $P$ waves sometimes with $S$ waves, and recently extended to estimate the fault length and fracture velocity from long-period body and surface waves or free oscillations, on the assumption that faulting process may be idealized by a moving point source. The introduction of the concept of elastic dislocation as a fault model has directed attention towards important source parameters including the seismic moment, the amount of dislocation, fault area, source time function, and stress-strain drop at the source region (AKI, 1966, 1968).

It has not yet been well established, however, that intermediate and deep focus earthquakes might be generated in similar physical processes as large shallow earthquakes, al- though some observational attempts have been made from spectral analysis (TeNG and BeNMenahem, 1965) or time domain analysis (Bollinger, 1968) of long-period $P$ waves. It is the purpose of this paper to investigate whether the source mechanism of intermediate depth earthquakes could be interpreted in terms of moving shear dislocations as in the case of shallower earthquakes, and, if faulting is the cause of the earthquakes, to what extent the various source parameters could be estimated from the $P$ waveforms recorded on seismograms.

The nature of the seismic waves radiated from the source are distorted by the properties of the medium during propagation through the mantle and crust and by a recording instrument. One way of removing these effects is the equalization of observed wave spectrum to the source region, by an inverse filtering process (Ben-Menahem et al., 1965). In this method, the equalized amplitude and phase spectra involve the effects of the source time function and of the source finiteness, and cannot be expected to provide independent information for the parameters. The alterna- 
tive method mainly pursued in this study is to construct synthetic seismograms of direct $P$ waves from appropriately assumed dislocation models, taking into account the combined effects of propagation and instrument, and to compare them with observed waveforms. It is expected that the comparison will give estimates for possible ranges of the source parameters. The processes at the source of intermediate earthquakes will be tentatively discussed.

\section{§2. Data}

Four intermediate earthquakes with magnitudes from 6.0 to 6.5 are dealt with in this study, which occurred along island arcs from New Guinea to the Fiji Islands at depths between 100 and $200 \mathrm{~km}$. Data used are the long-period vertical component seismograms recorded at stations of the World-wide Standardized Seismograph Network. Table 1 gives the information pertinent to the earthquakes, including their fault-plane solution which has been determined in a previous work (Mrno, Onoguchi and Mrkumo, 1968). The locations of the recording stations, for which the seismograms will be analyzed, are listed in Table 2.

The radiation patterns of $P$ wave first motion on the Wulff-net projection are reproduced in Figs. 9, 11, 13 and 15, for the four earthquakes respectively. The solution for earthquake No. 6 has been modified according to that obtained by ISACKs et al. (1968), because the latter included more data from near stations. It may be reasonable to infer from the patterns together with $S$ wave polarization (Mino et al., 1968) that these earthquakes have the focal mechanism of doublecouple type. Although alternative hypotheses, such as volume change due to phase transitions, as has been suggested by Evison (1967), cannot totally be ruled out, it appears that our data not only from the mentioned four earthquakes but also from other eight intermediate shocks in this region (Mino et al., 1968) definitely favor the double-couple source. This situation would allow us to postulate shear dislocation models as more general, theore- tical basis to this type of mechanism, in accordance with the case of shallower earthquakes.

\section{§3. Theoretical Treatment}

Theoretical studies on elastic body waves from dislocation models have been made by KnOpoff and Gilbert $(1959,1960)$, Maruyama (19.63), Haskell (1964), BurRIDGe and KNopofF (1964), and SAYAGE $(1965,1966)$, although a finite moving source has also been treated from somewhat different standpoint by BENMenahem (1962) and Hirasawa and Stauder (1965). Maruyama (1963) has demonstrated an important fact that dynamic dislocations or discontinuity of displacement or stress across a plane are exactly equivalent to some combinations of dynamic body forces. This paper starts from his results.

The displacement $u_{m}(Q, t)$ at any point $Q$ in an infinite homogeneous elastic medium due to the displacement discontinuity $\Delta u_{k}(t)$ over a plane $\Sigma$ can be written in the following form, from equation 34 of MaruYama (1963),

$$
\begin{gathered}
u_{m}(Q, t)=\frac{1}{2 \pi} \int_{-\infty}^{\infty} e^{i \omega t} d \omega \iint \Delta \bar{u}_{k}(\omega) T_{k l}^{m}(\omega) \nu_{l} d \Sigma \\
\Delta \bar{u}_{k}(\omega)=\int_{-\infty}^{\infty} \Delta u_{k}(t) e^{-i \omega t} d t
\end{gathered}
$$

$T_{l l t}^{m}(\omega) e^{i \omega t}$, which is the $m$-component of the displacement field from equivalent dynamic double forces acting along the $k$ - and $l$-axes, has been given in equation 35 in his paper, but for the radial component at long distances, it may be approximated by,

$$
T_{k l}^{m}(\omega) \cong \frac{i \omega}{4 \pi a r} \cdot \frac{e^{-i \omega r / a}}{\lambda+2 \mu}\left(\lambda \delta_{k l} \frac{r_{m}}{r}+2 \mu \frac{r_{m}}{r} \frac{r_{k}}{r} \frac{r_{l}}{r}\right)
$$

neglecting the terms with orders higher than $(1 / r)^{2}$.

We shall consider first the case of slip dislocation $\left(\delta_{k l}=0\right)$ along a plane. If the $y z$ plane is taken to be the slip plane along which the dislocation occurs in the $y$-direction, the equivalent double-couple forces are oriented along the $x$-and $y$-axes respectively. In this case, eq. (3) may be rewritten as, 
Table 1. Information of the earthquakes analyzed.

\begin{tabular}{|c|c|c|c|c|c|c|c|c|}
\hline $\begin{array}{c}\text { Shock } \\
\text { No. }\end{array}$ & Date & $\begin{array}{l}\text { Origin time } \\
\mathrm{h} \mathrm{m} \mathrm{s}\end{array}$ & Lo & ${ }_{\lambda}^{\text {tion }}$ & $\begin{array}{c}\text { Depth } \\
\mathrm{km}\end{array}$ & Magnitude & $\begin{array}{c}\text { Plane A } \\
\text { s. d. }\end{array}$ & $\begin{array}{c}\text { Plane B } \\
\text { s. d. }\end{array}$ \\
\hline 6 & 1963 July 4 & $10 \quad 58 \quad 13.2$ & $26: 3 \mathrm{~S}$ & $177: 7 \mathrm{~W}$ & 158 & 6.5 & $107^{\circ} 25^{\circ}$ & $211^{\circ} 28^{\circ}$ \\
\hline 12 & 1964 Jan. 20 & $17 \quad 18 \quad 37.4$ & $20.7 \mathrm{~S}$ & $169.9 \mathrm{E}$ & 141 & 6.1 & $75 \quad 61$ & $139 \quad 52$ \\
\hline 15 & 1964 Apr. 24 & $\begin{array}{llll}05 & 56 & 10.1\end{array}$ & $5.1 \mathrm{~S}$ & $144.2 \mathrm{E}$ & 106 & 6.5 & 171 & 1716 \\
\hline 23 & $1966 \mathrm{Feb}, 4$ & $10 \quad 39 \quad 12.2$ & $15.9 \mathrm{~S}$ & $167.9 \mathrm{E}$ & 190 & 6.0 & 86 & $124 \quad 62$ \\
\hline
\end{tabular}

s.: strike, d.: dip

Table 2. Recording stations.

\begin{tabular}{|c|c|c|c|c|c|c|c|}
\hline $\begin{array}{c}\text { No. } 15 \\
\text { No. }\end{array}$ & Station & $\stackrel{\Delta}{(\mathrm{deg} .)}$ & $\begin{array}{c}\Phi \\
(\operatorname{deg} .)\end{array}$ & $\begin{array}{c}\text { No. } 12 \\
\text { No. }\end{array}$ & Station & $\stackrel{4}{(\operatorname{deg} .)}$ & $\begin{array}{c}\Phi \\
(\operatorname{deg} .)\end{array}$ \\
\hline 2 & COL & 85.5 & 23.0 & 1 & CMO & 91.3 & 16.7 \\
\hline 3 & CMC & 98.7 & 22.0 & 2 & GSC & 89.0 & 53.3 \\
\hline 4 & $\mathrm{COR}$ & 95.3 & 46.0 & 3 & TUC & 92.3 & 56.4 \\
\hline 5 & BKS & 95.9 & 53.0 & 4 & AFI & 18.7 & 71.8 \\
\hline 6 & KIP & 62.4 & 63.0 & 5 & WEL & 20.9 & 169.7 \\
\hline 7 & AFI & 44.2 & 105.0 & 6 & SBA & 57.2 & 180.8 \\
\hline 8 & RIV & 29.3 & 168.0 & 8 & MUN & 49.0 & 245.2 \\
\hline 9 & MAN & 30.2 & 311.0 & 9 & $\mathrm{RAB}$ & 23.8 & 311.2 \\
\hline 10 & $\mathrm{BAG}$ & 31.7 & 313.0 & 10 & PMG & 24.6 & 293.8 \\
\hline 11 & HKC & 40.1 & 314.0 & 12 & $\mathrm{BAG}$ & 60.9 & 303.6 \\
\hline 12 & NDI & 72.5 & 302.0 & 13 & NHA & 68.0 & 293.2 \\
\hline 13 & $\mathrm{LAH}$ & 75.7 & 304.0 & 14 & $\mathrm{CHG}$ & 79.8 & 294.5 \\
\hline 14 & QUE & 81.6 & 301.0 & 15 & HOW & 90.4 & 293.7 \\
\hline 15 & NHA & 38.8 & 297.0 & 16 & SHL & 88.6 & 297.9 \\
\hline 16 & MUN & 37.4 & 221.0 & 18 & RIV & 21.1 & 227.9 \\
\hline No. 6 & & & & No. 23 & & & \\
\hline 1 & HNR & 27.0 & 305.0 & 1 & $\mathrm{RAB}$ & 19.4 & 305.0 \\
\hline 2 & $\mathrm{RAB}$ & 36.3 & 301.0 & 2 & PMG & 21.2 & 285.5 \\
\hline 3 & $\mathrm{PMG}$ & 37.3 & 290.0 & 3 & $\mathrm{BAG}$ & 56.7 & 304.0 \\
\hline 4 & CTA & 33.6 & 272.5 & 4 & $\mathrm{HKC}$ & 64.9 & 304.0 \\
\hline 5 & MAN & 72.1 & 297.5 & 5 & NHA & 64.4 & 292.5 \\
\hline 6 & SEO & 82.1 & 320.0 & 6 & SHL & 84.7 & 297.5 \\
\hline 7 & $\mathrm{BAG}$ & 73.5 & 301.0 & 7 & HOW & 86.7 & 293.0 \\
\hline 8 & ANP & 77.9 & 306.0 & 8 & KOD & 93.2 & 279.0 \\
\hline 9 & $\mathrm{HKC}$ & 81.8 & 300.0 & 9 & LEM & 59.6 & 270.0 \\
\hline 10 & KIP & 51.1 & 23.5 & 10 & MUN & 49.4 & 242.0 \\
\hline 11 & COR & 86.3 & 33.0 & 11 & $\mathrm{ADE}$ & 32.3 & 227.5 \\
\hline 12 & DUG & 89.5 & 41.0 & 12 & RIV & 23.4 & 217.0 \\
\hline 13 & GOL & 94.0 & 53.0 & 13 & SPA & 74.2 & 180.0 \\
\hline 14 & LUB & 93.4 & 59.0 & 14 & SBA & 62.0 & 179.0 \\
\hline 15 & ALQ & 90.8 & 50.0 & 15 & WEL & 26.0 & 168.0 \\
\hline
\end{tabular}

$\Delta$ : epicentral distance, $\Phi$ : azimuth measured clockwise from the north 


$$
T_{y_{x}}^{r}(\omega) \nu_{x}=\frac{i \omega}{2 \pi a r}\left(\frac{b}{a}\right)^{2} \sin ^{2} \theta \cdot \sin \varphi \cdot \cos \varphi \cdot e^{-i \omega r / a},
$$

referring to the spherical coordinate system: $x=r_{0} \sin \theta \cdot \sin \varphi, y=r_{0} \sin \theta \cdot \cos \varphi, z=r_{0} \cos \theta$, where $a=\sqrt{(\lambda+2 \mu) / \rho}$ and $b=\sqrt{\mu / \rho}$ being the velocities of $P$ and $S$ waves. It is clear from

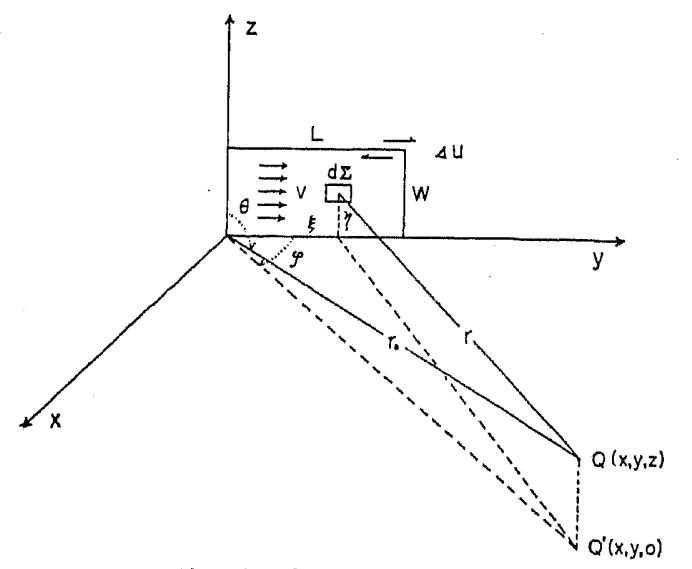

Fig. 1. Source geometry.

simple geometry in Fig. 1 that the distance $r$ from the surface element $d \Sigma$ to a point $Q$ is

$$
\left.\begin{array}{rl}
r^{2}= & \left(r_{0} \sin \theta\right)^{2}+\xi^{2}-2 r_{0} \sin \theta \cdot \xi \cos \varphi \\
& +\left(r_{0} \cos \theta-\eta\right)^{2} \\
r \cong & r_{0}-\xi \sin \theta \cdot \cos \varphi-\eta \cos \theta
\end{array}\right\} .
$$

Putting eqs. (2) and (4) into (1) and integrating the contributions over $\Sigma$, we obtain the displacement field $u_{r}(Q, t)$, but it seems appropriate before doing this to consider a faulting process here. SAVAGE (1966) has suggested that the slip dislocation or relative motion between two sides of the fault surface initiates at some point on the surface and then a dislocation front spreads outward on that surface at a finite velocity. We assume, as a first step representing the process, a finite moving dislocation with unilateral type of faulting over a rectangular surface. Suppose that the fault displacement initiates at $t=0$ over a width $W$ of the $z$-axis, and at any point $\xi$ on the fault plane, it occurs at $t=\xi / v$, propagating with a constant fracture velocity $v$ over a length $L$ along the $y$-axis. For this type of moving edge dislocation, eq. (2) should be replaced by,

$$
\Delta \bar{u}_{y}{ }^{\prime}(\omega)=\int_{-\infty}^{\infty} \Delta u_{y}(t-\xi / v) e^{-i \omega t} d t=\Delta \bar{u}_{y}(\omega) e^{-i \omega \xi / v} .
$$

From eqs. (4), (5) and $\left(2^{\prime}\right)$, the integration in (1) over the slip plane turns out to be,

$$
\begin{aligned}
\iint e^{-i \omega r / a} \cdot e^{-i \omega \xi / v} d \Sigma & =\int_{0}^{W} d \eta \int_{0}^{L} \exp \left[-i \omega\left(r_{0}-\xi \sin \theta \cdot \cos \varphi-\eta \cos \theta\right) / a-i \omega \xi / v\right] d \xi \\
& =L W \cdot \frac{\sin \omega T_{L}}{\omega T_{L}} \cdot \frac{\sin \omega T_{W}}{\omega T_{W}} \exp \left[-i \omega\left(r_{0} / a+T_{L}+T_{W}\right)\right],
\end{aligned}
$$

where $T_{L}$ and $T_{W}$ are given in eq. (9). Finally, the radial component of the displacement field can be expressed in the form,

$$
u_{r}(Q, t)=\frac{1}{2 \pi} \int_{-\infty}^{\infty} \dot{U}(\omega) \cdot S(\omega) \cdot \exp \left(-i \omega r_{0} / a\right) / r_{0} \cdot e^{i \omega t} d \omega
$$

where

$$
\dot{U}(\omega)=i \omega \Delta \bar{u}_{y}(\omega)=\int_{-\infty}^{\infty} \Delta \dot{u}_{y}\left(t^{\prime}\right) e^{-i \omega t^{\prime}} d t^{\prime}
$$

Since the time function of dislocation may not be very far from a step function, we assume the following two ramp functions.

$$
\begin{array}{ll}
\Delta u_{y}\left(t^{\prime}\right)=\left\{\begin{array}{ll}
D t^{\prime} / \tau \cdot H\left(t^{\prime}\right) & \left(0<t^{\prime}<\tau\right) \\
D & \left(t^{\prime}>\tau\right)
\end{array},\right. & \dot{U}(\omega)=\frac{D \sin (\omega \tau / 2)}{\omega \tau / 2} \exp (-i \omega \tau / 2) \\
\Delta u_{y}\left(t^{\prime}\right)=D\left(1-e^{-t^{\prime} / \tau}\right) H\left(t^{\prime}\right), & \dot{U}(\omega)=\frac{D}{\sqrt{1+\omega^{2} \tau^{2}}} \exp \left[-i \tan ^{-1}(\omega \tau)\right],
\end{array}
$$


where $D$ is the amount of dislocation, $t^{\prime}=t-\xi / v$, and $H\left(t^{\prime}\right)$ is the Heaviside unit step function. The source finiteness factor $S(\omega)$ is,

and

$$
S(\omega)=\frac{L W}{2 \pi a}\left(\frac{b}{a}\right)^{2} \alpha_{1} \alpha_{2} \cdot\left|\frac{\sin \omega T_{L}}{\omega T_{L}} \cdot \frac{\sin \omega T_{W}}{\omega T_{W}}\right| \exp \left[-i \omega\left(T_{L}+T_{W}\right)\right],
$$

$$
T_{L}=\frac{L}{2}\left(\frac{1}{v}-\frac{\alpha_{2}}{a}\right) \quad \text { and } \quad T_{W}=\frac{W}{2} \frac{\alpha_{3}}{a}
$$

where $\alpha_{j}(j=1,2,3)$ are the direction cosines of the vector $r$ relative to the $x$-, $y$ - and $z$-axes respectively.

For a moving screw dislocation in which the dislocation occurs in the $z$-direction with the fracture propagating in the $y$-axis, the equivalent forces are directed along the $x$ - and $z$-axes. Eq. (4) should be written for $T_{z x}^{r}(\omega)$ and $\left(2^{\prime}\right)$ for $\Delta u_{z}(t-\xi / v)$, and consequently, $\alpha_{1} \alpha_{2}$ in $S(\omega)$ should be replaced by $\alpha_{1} \alpha_{3}$. Eq. (7) with the replaced form of (8) and (9) has essentially the same form, except constants, as that derived by HIRASAWA and STAUDER (1965) from the integration of double-couple point source.

It is more convenient for practical purposes to refer to the geographical coordinate at the focus: $X=r_{0} \sin \Theta \cdot \sin \Phi, Y=r_{0} \sin \Theta \cdot \cos \Phi, Z$ $=r_{0} \cos \Theta$, with $\Theta=\pi-i_{h}, i_{h}$ being the take-off angle of a ray and $\Phi$ the azimuth measured clockwise from the north. Then we have

$$
\left(\begin{array}{l}
\alpha_{1} \\
\alpha_{2} \\
\alpha_{3}
\end{array}\right)=\left(\begin{array}{l}
\sin \theta \cdot \sin \varphi \\
\sin \theta \cdot \cos \varphi \\
\cos \theta
\end{array}\right)=\left(\begin{array}{lll}
l_{1} & m_{1} & n_{1} \\
l_{2} & m_{2} & n_{2} \\
l_{3} & m_{3} & n_{3}
\end{array}\right)\left(\begin{array}{l}
\sin \theta \cdot \sin \Phi \\
\sin \theta \cdot \cos \Phi \\
\cos \Theta
\end{array}\right)
$$

or

$$
\alpha_{j}=l_{j} \sin \Theta \sin \Phi+m_{j} \sin \Theta \cos \Phi+n_{j} \cos \Theta
$$
and

$$
l_{j}=\cos \phi_{j} \sin \beta_{j}, m_{j}=\cos \phi_{j} \cos \beta_{j}, n_{j}=\sin \phi_{j}
$$

$\left(l_{j}, m_{j}, n_{j}\right)$ are the direction consines of the equivalent force system relative to the new coordinate, that is, the cases $j=1,2$ and 3 correspond to those of a couple of forces perpendicular to the slip plane, another couple of forces parallel to the plane, and of the null vector respectively, and $\phi_{j}$ and $\beta_{j}$ are their plunge and azimuth.

If the source dimensions $L$ and $W$ are small compared with wavelength, eq. (9) reduces to

$$
S(\omega)=(L W / 2 \pi a)(b / a)^{2} \alpha_{1} \alpha_{2} \equiv S_{0},
$$

and this corresponds to the case of doublecouple point source. It is evident from comparison with the point source theory (cf. HoNDA, 1962) that the seismic source moment can be expressed by $M_{0}=K \delta s=\mu D L W$, as has been defined by AkI (1966).

The displacement field from bilateral faulting can be obtained by adding the displacements due to two unilateral faulting propagating in opposite directions (with two different signs of $v$ ).

There could be different types of dislocation. The case of normal discontinuity of displacement $\left(\delta_{k l}=1\right)$ is equivalent to the force system with a combination of a center of compression and a double force without moment (MaruYaMa, 1963). This case would correspond to the case when magma or some fluid intrudes into cracks and crevasses in the wall of a cavity in the earth's material, as has been suggested by IsHimoto (1932) and treated statically in term of $A$-nucleus by Staketтex (1958). If the crack propagates with a constant displacement and finite velocity over a rectangular surface, the same computation applies to this case as in the case of slip dislocation, except that $\alpha_{1} \alpha_{2}$ of $S(\omega)$ in eq. (9) has to be replaced simply by $\alpha_{1}{ }^{2}-1+(a / b)^{2} / 2$. This would provide the first motion pattern with either of all compression or dilatation, depending on the sense of normal discontinuity.

\section{§4. Effects of Propagation in the Earth}

In this study, we assume that the combined effects of wave propagation in the earth and the instrument can be idealized as a linear system for each ray path (Ben-Menahem et 
al., 1965). The effects may be specified by the source crust-mantle response $C_{M}(\omega)$, mantle transfer function $P(\omega)$ including geometrical spreading and attenuation, crustal response $C(\omega)$ under a recording station and instrumental response $I(\omega)$.

1) The source crust-mantle response $C_{M}(\omega)$ of $P$ waves for the case of multilayered crust containing a point source has been formulated by Fuchs (1967). Fuchs (personal communication, 1968) gave some examples of the amplitude and phase responses from an explosive source at depths of 100 and $200 \mathrm{~km}$ for his standard crust NOCR (1967), which indicates that the surface reflection $p P$ gives strong effect on the spectra. Since the later phase would appear at about $30 \mathrm{sec}$ after the onset, in the case of the intermediate depths, the effect does not seem important in the time domain analysis of direct $P$ waves. For this reason, $C_{M}(\omega)$ has been omitted here.

2) In general, the seismic disturbance on the earth's surface due to body waves can be expressed by the superposition of normal modes in a gravitating spherical earth. It has been shown (UsAmi et al., 1968) that in order to represent the waveform of $P$ waves, it is necessary to sum up contributions from radial higher overtones of free spheroidal oscillations, and that the variations of its amplitude with epicentral distances agree with those expected from geometrical optics using the divergence factor. In this sense, the transfer function $P(\omega)$ should take a complicated form for $\omega$, but for periods not very long, the spectrum might be approximated as having a week frequency dependence. The relation between a normal mode and the corresponding parameters of the ray trajectory associated with the mode has also been discussed, and shown to be approximated by geometrical spreading for direct waves (BENMenahem et al., 1965).

For these reasons, we may be allowed to express the mantle transfer function $P(\omega)$ for direct $P$ waves with periods under consideration, as a first approximation, by the product of geometrical speading and attenuation,

$$
P(\omega)=G \cdot \exp (-\omega T / 2 \bar{Q}) \cdot \exp (-i \omega T),
$$

where

$$
\begin{aligned}
& G=\frac{1}{R}\left[\frac{\rho_{h} v_{h}}{\rho_{0} v_{0}} \cdot \frac{\sin i_{h}}{\sin \Delta \cdot \cos i_{0}}\left|\frac{d i_{h}}{d \Delta}\right|\right]^{1 / 2}, \\
& \frac{T}{\bar{Q}}=\int \frac{d s}{Q(r) v(r)}=\int \frac{\eta^{2}}{\sqrt{\eta^{2}-\rho^{2}}} \cdot \frac{d r}{r Q(r)},
\end{aligned}
$$

$\eta=r / v(r)$, and $p=\eta \sin i_{h}$. The above notations are; $T$ : travel time, $\rho$ : density, $v$ : velocity, $i$ : incident angle, $\Delta$ : epicentral distance, $R$ : radius of the earth. Suffixes $h$ and $o$ indicate quantities for the source and the earth's surface respectively. The term $1 / r_{0}$ in eq. (7) has been replaced simply by the divergence factor $G$ (HoNDA, 1962) for a spherical earth, and hence $\exp \left(-i \omega r_{0} / a\right)$ by $\exp (-i \omega T)$. These two terms yield the diminution of amplitude and absolute time delay of wave arrival respectively, but do not contribute to the waveshape. $\bar{Q}$ is the average attenuation along a ray path from source to station, depending on the intrinsic $Q$ structure within the mantle. Although several $Q$ models have been presented from observations of surface waves, free oscillations and body waves, we used a $Q$-model (Model 11) of Mikumo and Kurita (1968) derived from long-period $P$ waves. $P(\omega)$

Table 3. Crustal models.

\begin{tabular}{l|c|c|c|c}
\hline Station & $\begin{array}{c}\alpha \\
\mathrm{km} / \mathrm{sec}\end{array}$ & $\begin{array}{c}\beta \\
\mathrm{km} / \mathrm{sec}\end{array}$ & $\begin{array}{c}\rho \\
\mathrm{gr} / \mathrm{cm}^{3}\end{array}$ & $\begin{array}{r}H \\
\mathrm{~km}\end{array}$ \\
\cline { 1 - 4 } RIV & 4.50 & 2.60 & 2.55 & 2.0 \\
& 6.00 & 3.46 & 2.72 & 35.0 \\
KIP & 8.20 & 4.73 & 3.35 & \\
& 4.30 & 2.48 & 2.51 & 2.3 \\
& 6.60 & 3.81 & 2.83 & 4.7 \\
BKS & 7.90 & 4.56 & 3.27 & \\
& 5.50 & 3.18 & 2.65 & 3.0 \\
& 6.50 & 3.75 & 2.82 & 20.0 \\
AFI & 8.00 & 4.62 & 3.30 & \\
& 4.60 & 2.66 & 2.56 & 1.2 \\
& 6.40 & 3.70 & 2.80 & 4.6 \\
BAG & 8.20 & 4.73 & 3.35 & \\
& 5.50 & 3.18 & 2.65 & 3.1 \\
& 6.10 & 3.52 & 2.73 & 3.3 \\
CMO & 6.20 & 3.58 & 2.75 & 10.6 \\
& 8.00 & 4.62 & 3.30 & \\
& 3.60 & 2.08 & 2.44 & 2.0 \\
& 6.20 & 3.58 & 2.75 & 26.0 \\
& 7.20 & 4.16 & 3.03 & 14.0 \\
\hline
\end{tabular}

$\alpha: P$ wave velocity, $\beta: S$ wave velocity

$\rho$ : density,

$H$ : layer thickness 
was evaluated for each station by the use of $i_{h}-\Delta$ relation.

3) The effects of crustal layering under a recording station can be represented by the crustal transfer function $C(\omega)$, using the Thomson-Haskell matrix formulation (HasKELL, 1962), for plane waves with a specific angle of incidence to the base of the crust. The crustal structures under each station are not known very accurately at the present time, but were taken from all available sources of information (for example, McCoNNELL, 1966) as a first approximation. Table 3 gives the crustal models applied to the six stations in Fig. 2. $C(\omega)$ for the vertical component has been computed for each station.

4) The instrumental response $I(\omega)$ of the long-period seismograph-recording system used at the WWSSN has been computed from the equation,
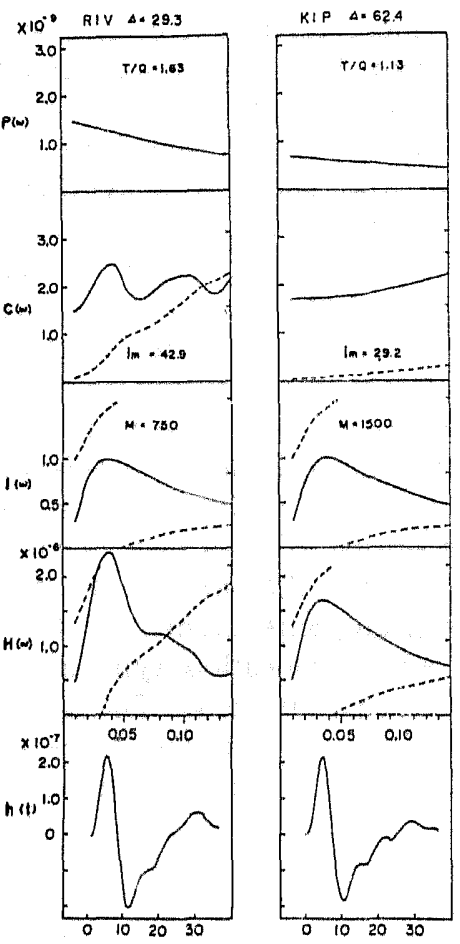

(a)
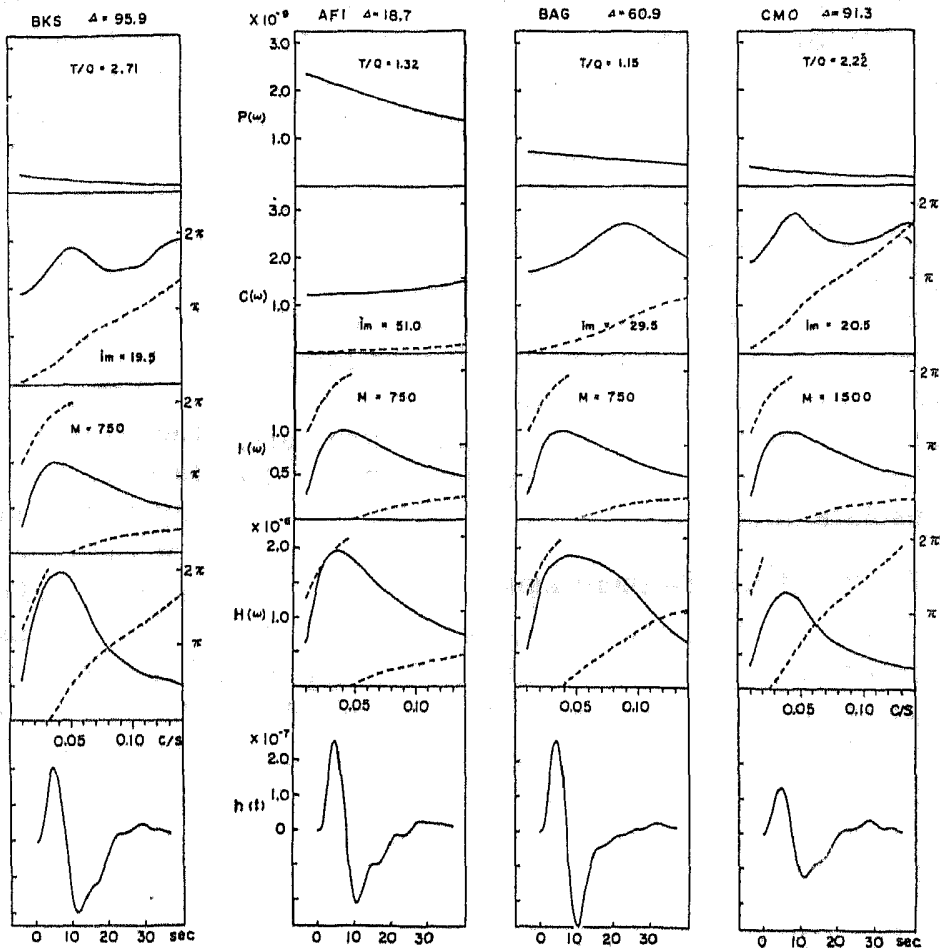

(b)

Fig. 2. Transfer functions and impulse responses of the earth-recording system,

(a) for 3 stations in earthq. No. 15, (b) for 3 stations in earthq. No. 12 .

$$
\left.\begin{array}{c}
I(\omega)=M \omega^{8} / \sqrt{[A(\omega)]^{2}+[B(\omega)]^{2}} \exp [-i \tan (-A(\omega) / B(\omega))] \\
A(\omega)=\left(\omega^{2}-\omega_{0}{ }^{2}\right)\left(\omega^{2}-\omega_{g}{ }^{2}\right)-4 \varepsilon_{0} \varepsilon_{g}\left(1-\sigma^{2}\right) \omega^{2} \\
B(\omega)=2 \omega\left[\varepsilon_{g}\left(\omega^{2}-\omega_{0}{ }^{2}\right)+\varepsilon_{0}\left(\omega^{2}-\omega_{g}{ }^{2}\right)\right]
\end{array}\right\}
$$

and $\omega_{0}=2 \pi / T_{0}, \omega_{g}=2 \pi / T_{g}$, where $T_{0}, T_{g}, \varepsilon_{0}$, and $\varepsilon_{0}$ are the free periods and damping coefficients of the pendulum and galvanometer respectively, and $\sigma^{2}$ is the coupling factor and $M$ is a normalization constant for magnification. The conventional system has con- stants of $T_{0}=30$ or $15 \mathrm{sec}, T_{g}=100 \mathrm{sec}, h_{0}=$ $h_{g}=1$ and $\sigma^{2} \cong 0$. The peak magnification ranges from 375 to 3000 .

5) The overall system transfer function $H(\omega)$ for the linear system under consideration may now be written in the form, 


$$
H(\omega)=C_{M}(\omega) \cdot P(\omega) \cdot C(\omega) \cdot I(\omega),
$$

where each of the transfer functions includes the real and imaginary parts or the amplitude and phase responses. The impulse response of the system is,

$$
h(t)=\frac{1}{2 \pi} \int_{-\infty}^{\infty} H(\omega) e^{i \omega t} d \omega .
$$

All computations of the Fourier transform and synthesis were made at an interval of $0.005 \mathrm{c} / \mathrm{s}$ in the frequency range between 0.005 and $0.15 \mathrm{c} / \mathrm{s}$. Figs. 2 (a) and $2(\mathrm{~b})$ show some examples of the transfer functions and the corresponding impulse responses for three selected stations in the case of earthquakes No. 15 and No. 12. The full and broken curves are the amplitude response and the phase response given in the delay between 0 and $2 \pi$. It can be seen from the figures that the shape of the system function or impulse response is not greatly affected by the differences in attenuation or crustal structure, although these terms give effects on the absolute amplitude.

\section{§5. Synthetic Seismograms}

From the theoretical considerations in the preceding sections, the synthetic seismogram $f(t)$ from dislocation sources which would be recorded at a station on the earth's surface, may be expressed by the convolution of the source function $u_{r}{ }^{0}(t)$ with the impulse response $h(t)$ of the earth-recording system,

$$
\begin{aligned}
f(t) & =\int_{0}^{\infty} u_{r}^{0}(\tau) h(t-\tau) d \tau \\
& =\frac{1}{2 \pi} \int_{-\infty}^{\infty} \dot{U}(\omega) \cdot S(\omega) \cdot H(\omega) e^{i \omega t} d \omega,
\end{aligned}
$$

where

$$
u_{r}{ }^{0}(t) \equiv \frac{1}{2 \pi} \int_{-\infty}^{\infty} \dot{U}(\omega) \cdot S(\omega) e^{i \omega t}
$$

The synthetic seismograms have been constructed for 15 stations selected from each of the four mentioned earthquakes, for various combinations of source parameters with the following assumptions: that the source dimension of intermediate earthquakes may be considerably smaller than that of shallow shocks with the same magnitudes $(L, W<$
$50 \mathrm{~km}$ ); that the fracture velocity does not exceed the $S$ wave velocity around the source region $(v<5 \mathrm{~km} / \mathrm{sec})$; and that the time function of dislocation may be approximated by a ramp function $(\tau<5 \mathrm{sec})$. In the following figures, we shall give only some representative cases to evaluate the effects of variations in the parameters.

Effects of the source dimension and direction of faulting

Earthquake No. 15 has a nearly horizontal (PL. 1) and an almost vertical (PL. 2) nodal planes, as seen from Fig. 9, but we cannot determine, without further information, which of the two planes should correspond to the slip plane. Fig. 3(a) shows the synthetic seismograms for station RIV in the case of unilateral faulting along PL. 1 with a fixed moment $\left(M_{0}=5.3 \times 10^{26} \mathrm{dyne} \cdot \mathrm{cm}\right)$, fracture velocity $(v=3.5 \mathrm{~km} / \mathrm{sec})$ and time constant $(\tau=1 \mathrm{sec})$. The direction of faulting (towards the west or east) yields no appreciable difference in the waveform, because the seismic ray to this station lies near PL. 2. This is not the case for station AFI as may be seen from Fig. 3(c). In Fig. 3(b) are shown the corresponding seismograms from unilateral faulting of the edge dislocation type along PL. 2 with the same parameters. The waveforms differ significantly for the cases of upward (full line) and downward (broken line) faulting. It may be seen in all cases of (a) and (b) that the increase in the fault length lengthens the time duration of pulses, and that variations in the fault width over the range indicated do not produce great effects on the waveforms. We also notice that all the seismograms for $L$ shorter than $20 \mathrm{~km}$ show a similar waveform to that from a point source. This suggests that the orientation of slip plane, fault length and direction of fracture propagation can not be estimated by this type of time domain analysis, if the length is shorter than $20 \mathrm{~km}$ in case of a fracture velocity around $3.5 \mathrm{~km} / \mathrm{sec}$. The same situation may also be noticed from Fig. 3(c).

\section{Effect of the fracture velocity}

Fig. 4 illustrates the effect of variations in the fracture velocity for westward horizontal 

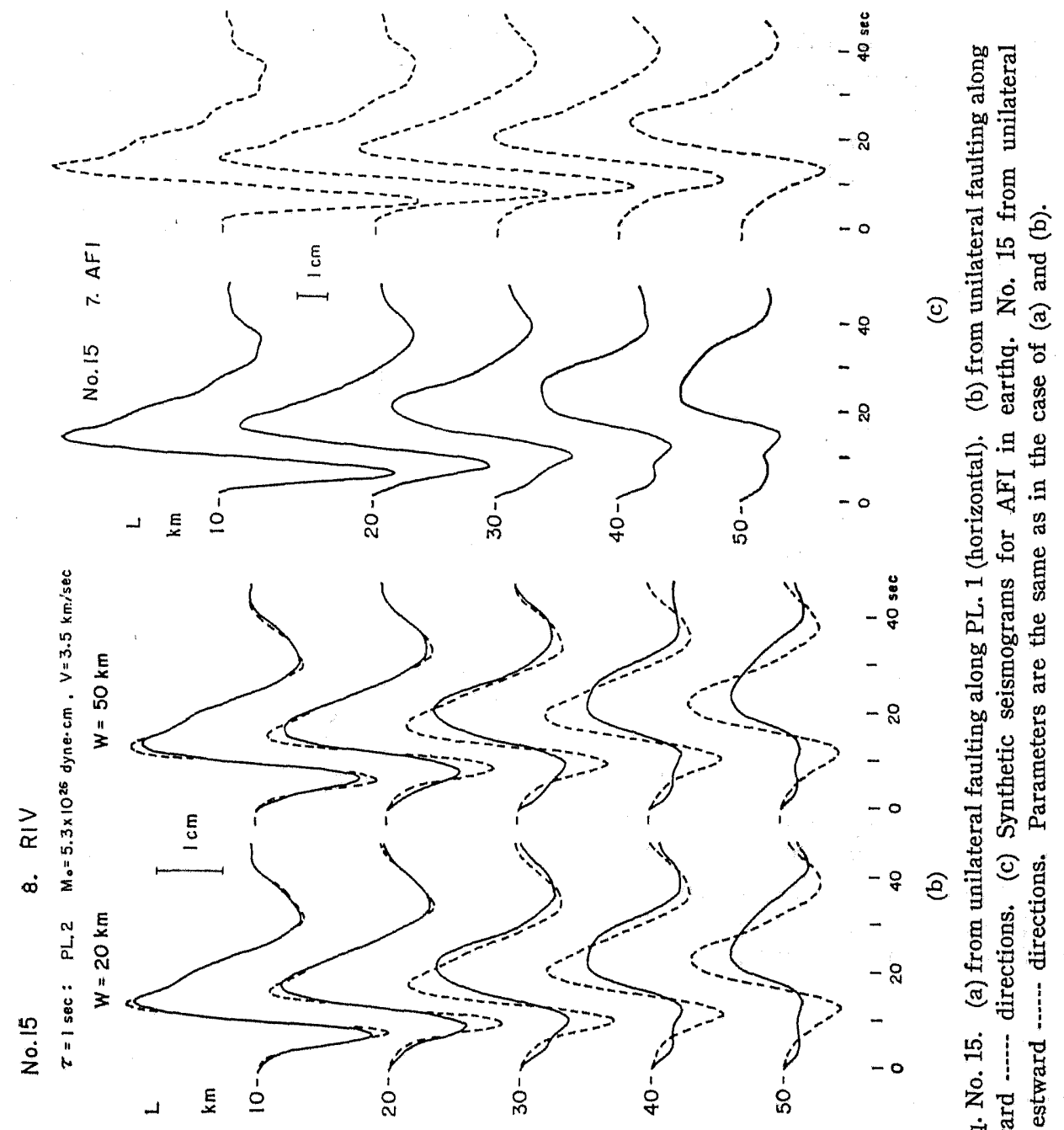

- \& อ 兽完学

- 焉要岁

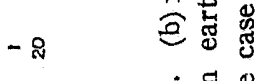

- 焉要吉

龸点

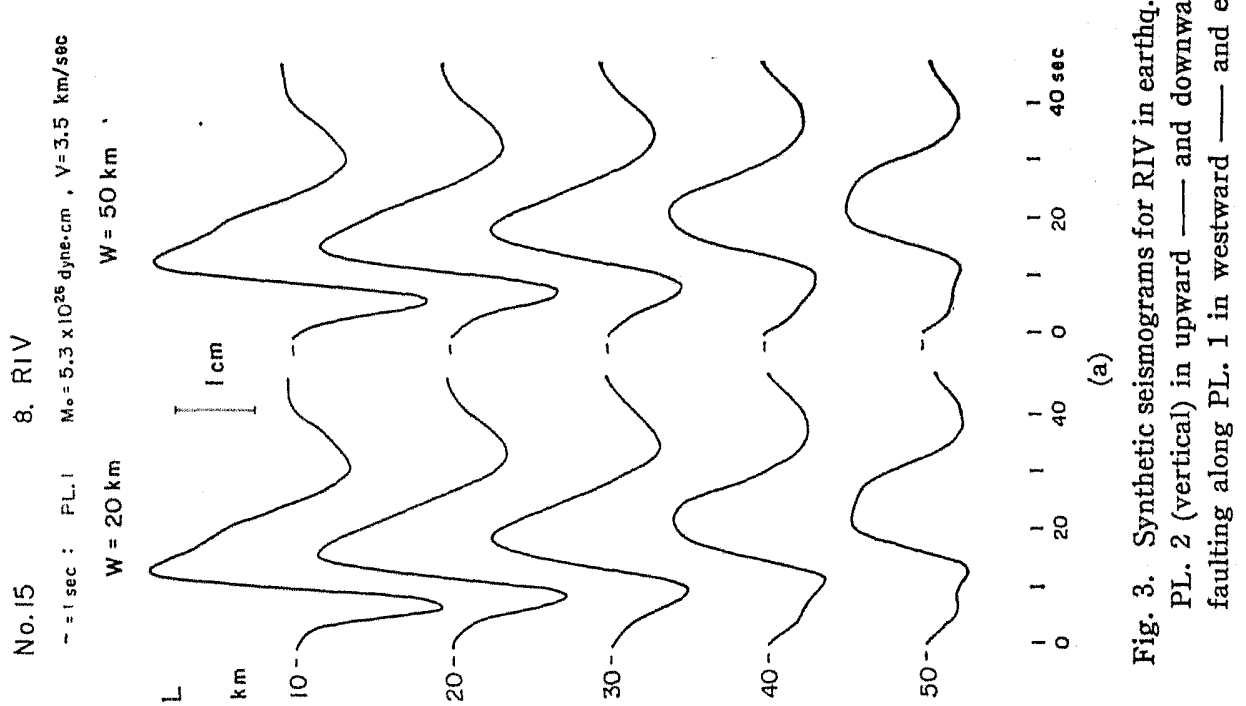




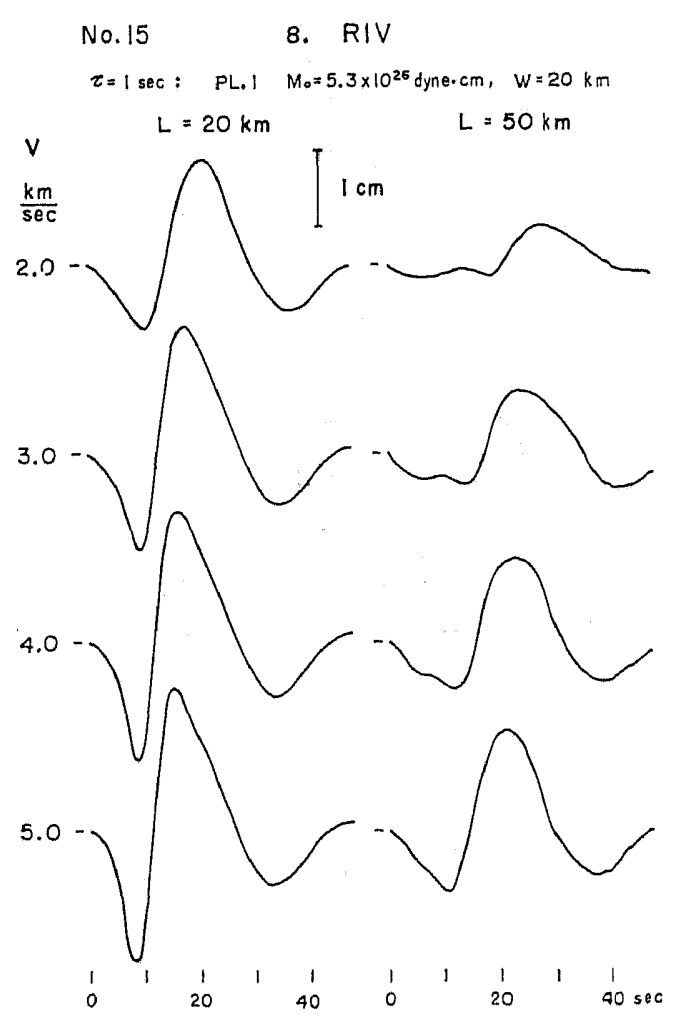

F.g. 4. Synthetic seismograms for RIV in earthq. No. 15 from unilateral faulting along PL. 1, for variations in the fracture velocity.

faulting, with a fixed fault width ( $W=20 \mathrm{~km}$ ) and with the same moment and time constant as above. We see that the time duration of pulses becomes longer as the velocity decreases, indicating a similar effect to the case of the increase of fault length.

\section{Azimuthal variations of the waveform}

To see variations in the waveform pattern over an adequate azimuthal coverage of stations, the synthesized seismograms appropriate to six selected stations in earthquake No. 15 are presented in Figs. $5(\mathrm{a})$ and $5(\mathrm{~b})$, for the cases of unilateral faulting along PL. 1 and PL. 2 respectively, with $L=30 \mathrm{~km}, W=20 \mathrm{~km}$, $v=3.5 \mathrm{~km} / \mathrm{sec}$ and $M_{0}=5.3 \times 10^{26}$ dyne $\cdot \mathrm{cm}$. Comparing the waveforms with the radiation pattern in Fig. 9, it is evident that the effective time duration becomes longer and the amplitude diminishes or vice versa at stations against or for which the fracture is propagated. The relation between the time duration and amplitude among the six stations are significantly different for the four cases of unilateral faulting. An attempt was made here to evaluate this relation to examine the

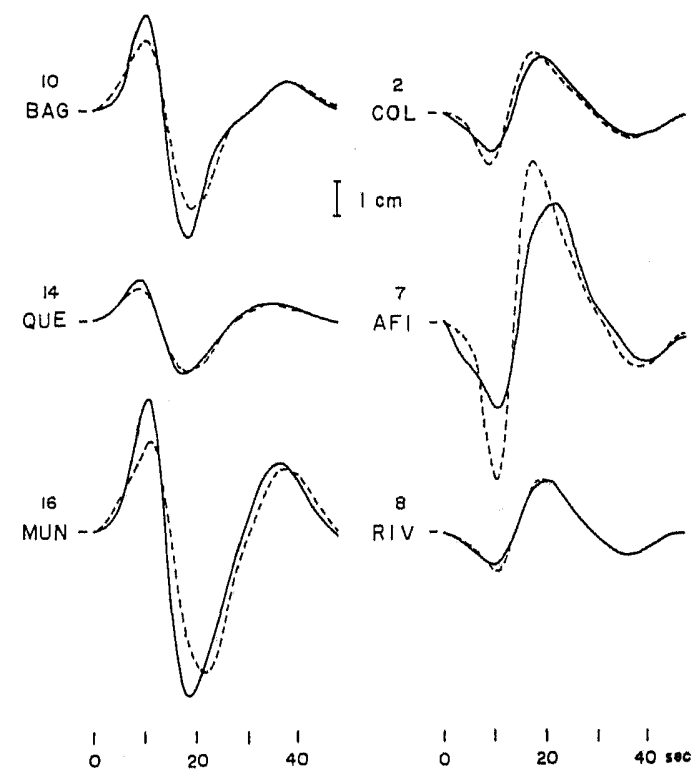

(a)

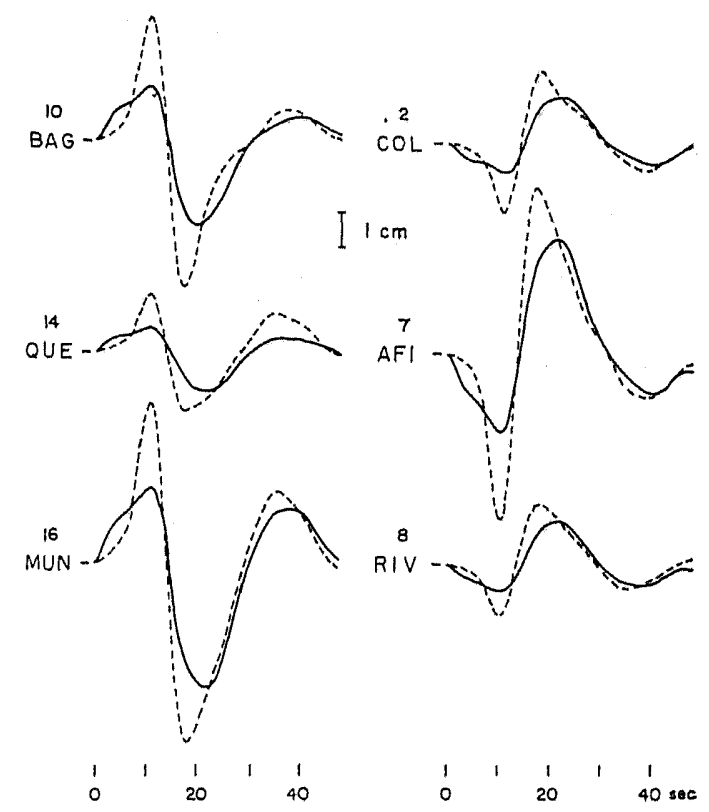

(b) 


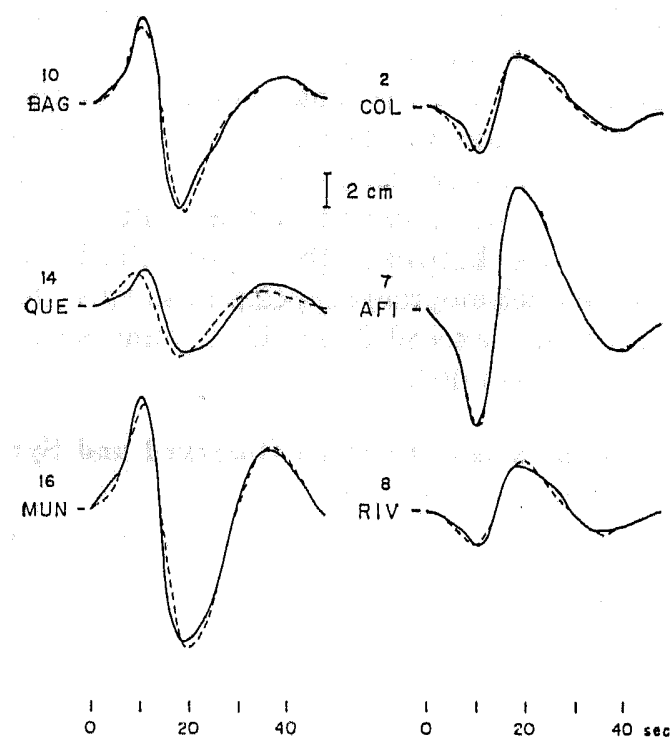

(c)

Fig. 5. Synthetic seismograms for 6 stations in earthq. No. 15, with $\tau=1 \mathrm{sec}, M_{0}=5.3 \times 10^{26}$ dyne. $\mathrm{cm}, v=3.5 \mathrm{~km} / \mathrm{sec}, L=30 \mathrm{~km}$, and $W=20 \mathrm{~km}$. (a) unilateral faulting along PL. 1 in westward and estward ...... directions. (b) unilateral faulting along PL. 2 in upward _- and downward ..... directions. (c) bilateral faulting along PL.

$1-$ and PL. 2 .......

possibility of discriminating the orientation of slip plane and direction of faulting. The average energy contained per unit time interval of the first one cycle or the corresponding amplitude may be defined and approximated by

$$
\left.\begin{array}{l}
\bar{e}=\frac{1}{T^{2}} \int_{0}^{T}[f(t)]^{2} d t \cong A^{2} / 4 T \\
\bar{a}=\frac{1}{T^{2}} \int_{0}^{T}|f(t)| d t \cong A / 2 T
\end{array}\right\},
$$

where $A$ is the maximum double amplitude and $T$ is the apparent period measured on seismograms. Fig. 6 depicts $\bar{a}$ plotted against $\alpha_{1} \alpha_{2}$. The four unilateral cases mentioned above indicate characteristic differences, and would be discriminated if the source dimension and fracture velocity are of the order assumed here. However, the waveforms for two cases of bilateral faulting along PL. 1 and PL. 2 (with $2 L=60 \mathrm{~km}$ ) do not show ap-

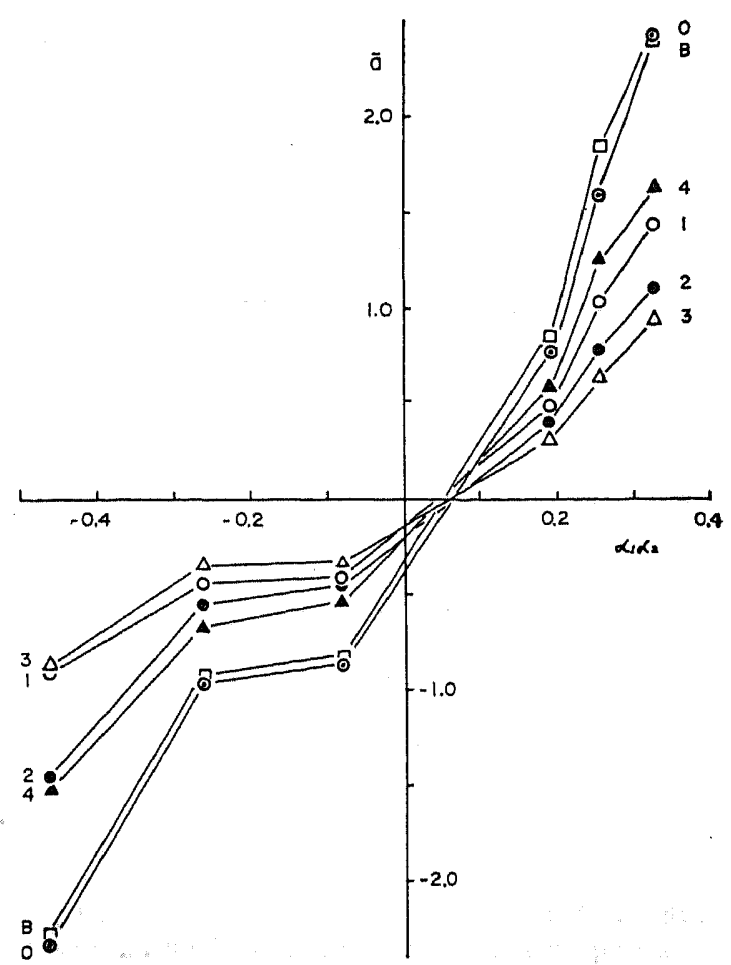

Fig. 6. Average amplitude per unit time interval of the first one cycle of the synthetic seismograms (for earthq. No. 15). 0 : point source. 1,2: unilateral faulting along PL. 1 ( $v \lessgtr 0)$. 3,4: unilateral faulting along PL. $2(v \leqq 0)$. B: bilateral faulting along PL. 1 and 2.

preciable disdrepancy as seen from Fig. 5(c), canceling out the features of unilateral faulting. The seismograms for a bilateral fault length less than $30 \mathrm{~km}$ would not be discriminated from those for a point source.

Another examples of the synthesized seismograms are shown in Fig. 7 for four selected stations in earthquake No. 12 . The four traces correspond to four cases of ulilateral faulting along a nodal plane (PL. 1) striking in the NW-SE direction and along the other plane (PL. 2) striking in nearly the E-W direction (See Fig. 11). There seem to be similar waveform relations to the case of earthquake No. 15.

Effect of the time constant of dislocation

It has been shown that if the fault length is shorter than $20 \mathrm{~km}$ in case of a fracture 


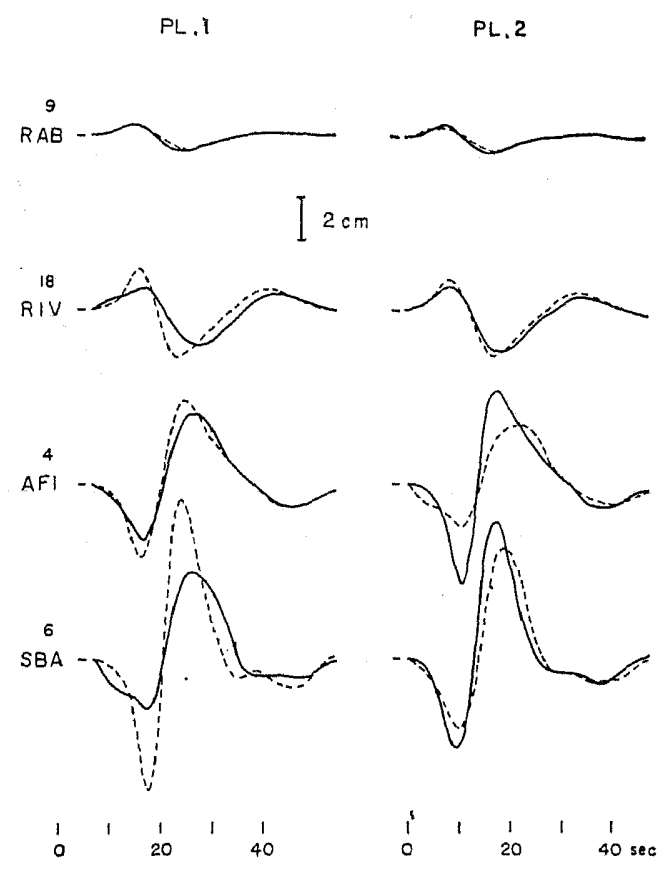

Fig. 7. Synthetic seismograms for 4 stations in earthq. No. 12 from unilateral faulting along PL. 1 and PL. $2(-v>0, \ldots . . v<0)$, with $\tau=$ $1 \mathrm{sec}, M_{0}=8.6 \times 10^{26} \mathrm{dyne} \cdot \mathrm{cm}, v=3.5 \mathrm{~km} / \mathrm{sec}, L=$ $30 \mathrm{~km}$ and $W=20 \mathrm{~km}$.

velocity higher than $3.5 \mathrm{~km} / \mathrm{sec}$ the waveform approaches those for a point source. In this case, $S(\omega)$ reduces to a constant $S_{0}$ independent on $\omega$ (eq. $\left(9^{\prime}\right)$ ), so that the synthetic waveform depends only on the time dependence of dislocation and the system response, as is evident from eq. (18). Figs. 8(a), (b) and (c) illustrate the effects of variations in the time constant for two stations each in earthquakes Nos. 15, 12 and 6, respectively. The seismograms shown here were computed from the ramp function of (8-b) type, but the use of (8-a) did not make much difference. The case of $\tau=0$ corresponds to a step function, that is, $\dot{U}(\omega)=D$, then we have, together with $S(\omega)=S_{0}$,

$$
\begin{aligned}
f(t) & =\frac{S_{0} D}{2 \pi} \int_{-\infty}^{\infty} H(\omega) e^{i \omega t} d \omega \\
& =S_{0} D h(t) \equiv k f_{0}(t),
\end{aligned}
$$

where $k=(D L W / 2 \pi a)(b / a)^{2}$, and $f_{0}(t)=\alpha_{1} \alpha_{2} h(t)$, and hence the waveform shows the impulse response of the earth-recording system. It can be seen that the lengthening of the time constant makes the duration longer and reduces the relative amplitude. This is a similar effect to an increase in the fault length. Comparison between the synthesized and observed seismograms appears to suggest that $\tau$ would not exceed $3 \mathrm{sec}$, if a point source model is assumed.

\section{§6. Comparison between Observed and Syn- thetic Seismograms}

Close examination of the observed records from the four intermediate earthquakes does not indicate such remarkable, azimuthal dependence of waveform characteristics as have been demonstrated in the synthetic seismograms for unilateral faulting. This suggests that the actual source of the earthquakes may be regarded as considerably small compared with wavelength even if a moving dislocation is assumed. For this reason, we tentatively compare here the observed records with the synthetic waveform $f_{0}(t)$ for a point source with a step function time dependence. Both kinds of the seismograms are normalized to a seismograph magnification of 1500 .

Fig. 9 shows the radiation pattern of $P$ wave first motions from earthquake No. 15. In Fig. 10 are displayed the observed and synthetic $P$ waveforms at the stations numbered in Fig. 9. It may be seen that there is generally a good agreement between the waveforms particularly around the first half cycle. The observed amplitude relation among these stations appears to be consistent with that expected from a double-couple point source, although the second peaks are sometimes smaller than theoretical prediction. This can be confirmed also from $\bar{a} \sim \alpha_{1} \alpha_{2}$ plots if the observed values are superposed on Fig. 6 . It is noticed, moreover, in most of the observed records that a phase-like pulse enters about $10 \sim 15 \mathrm{sec}$ after the onset of $P$ waves. Travel time curves for this earthquake predict no later phases around that time. The 'phase' may not be attributed to reverberations due to crustal inhomogeneity, since the effects are 

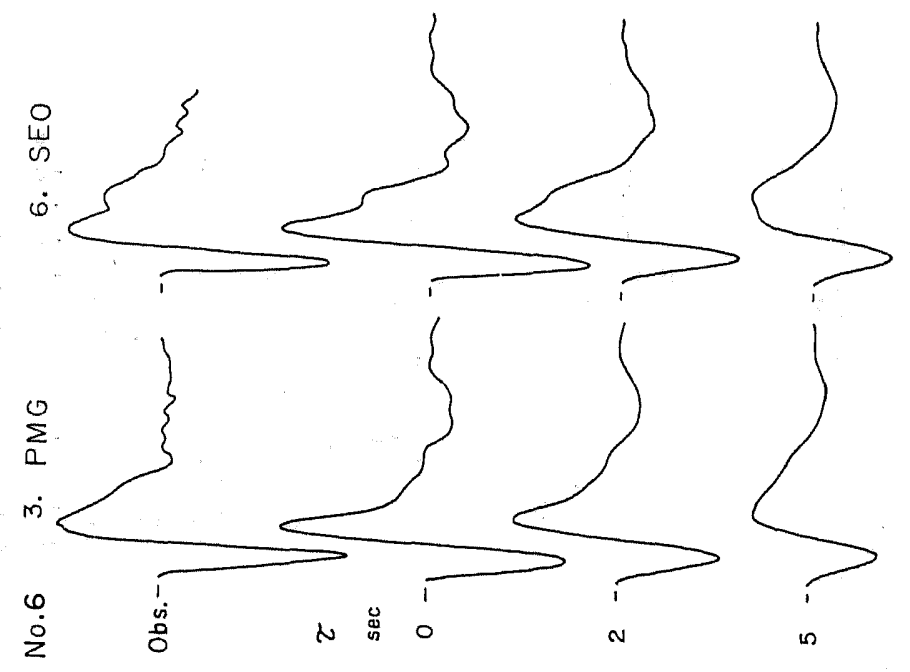

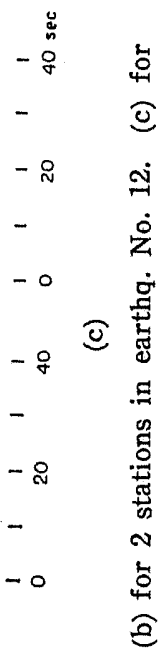
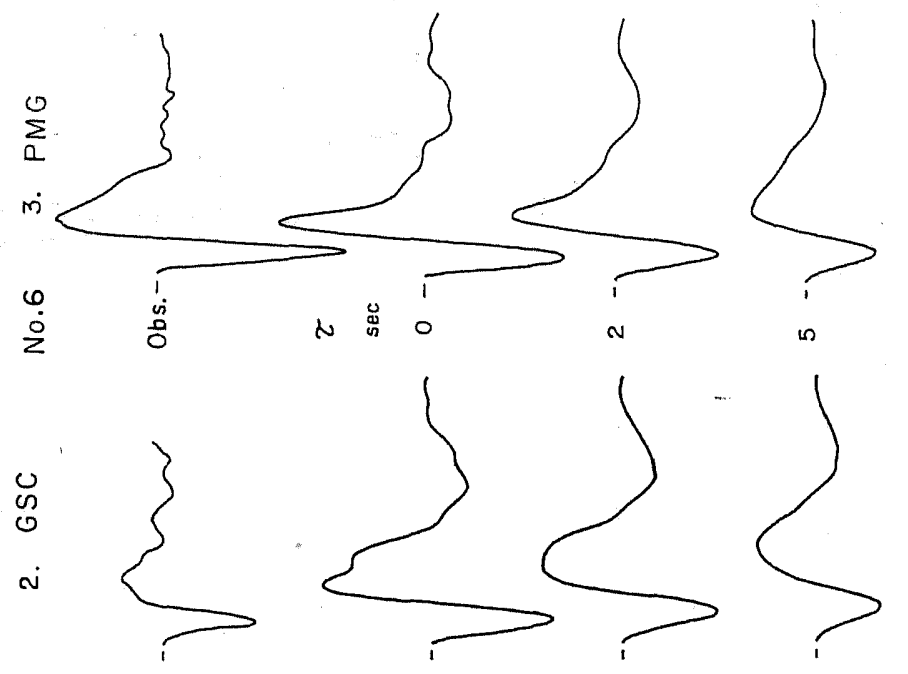

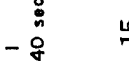

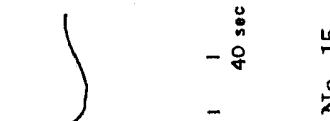

- 2 宾

- 0 อ.
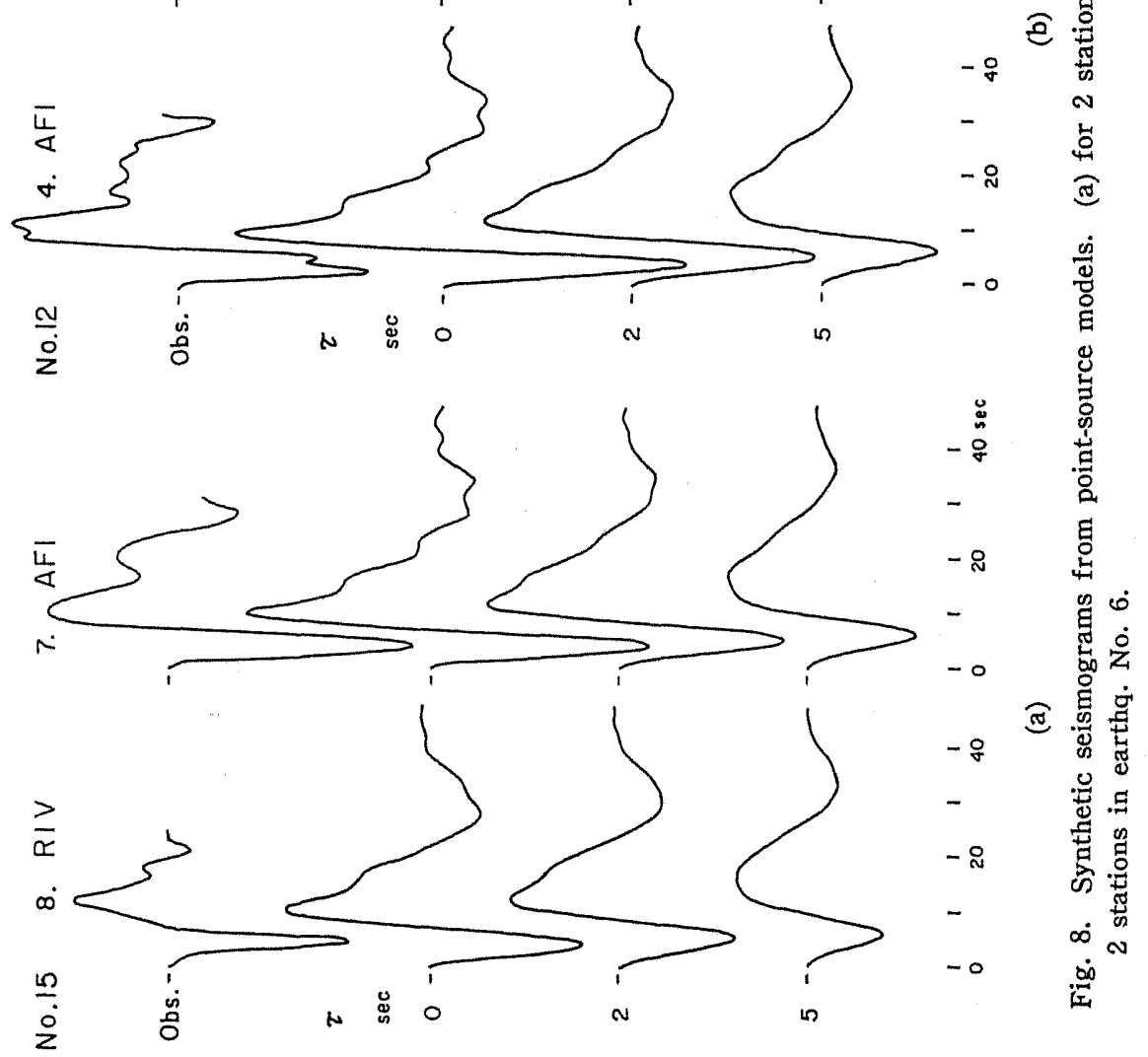

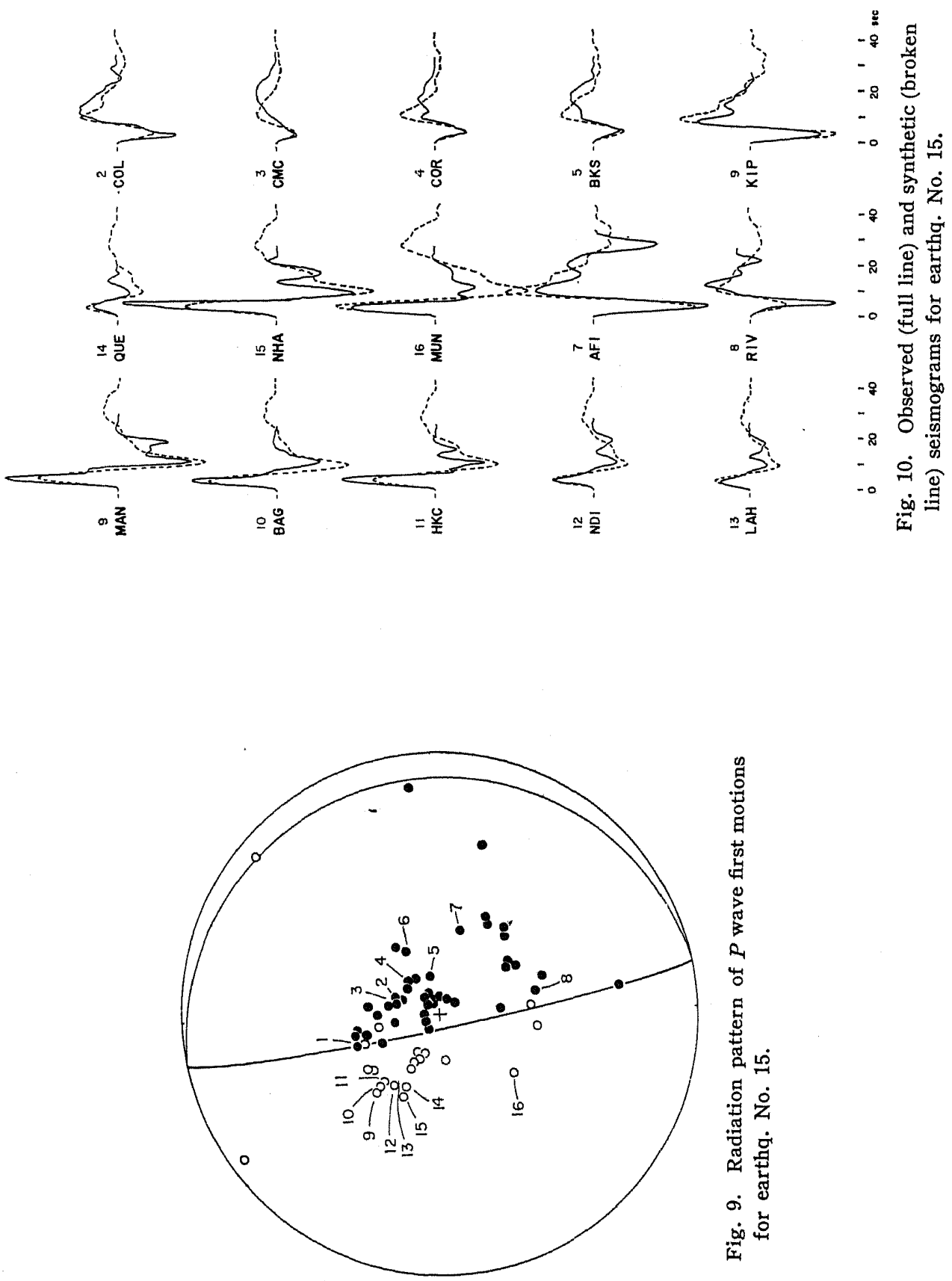

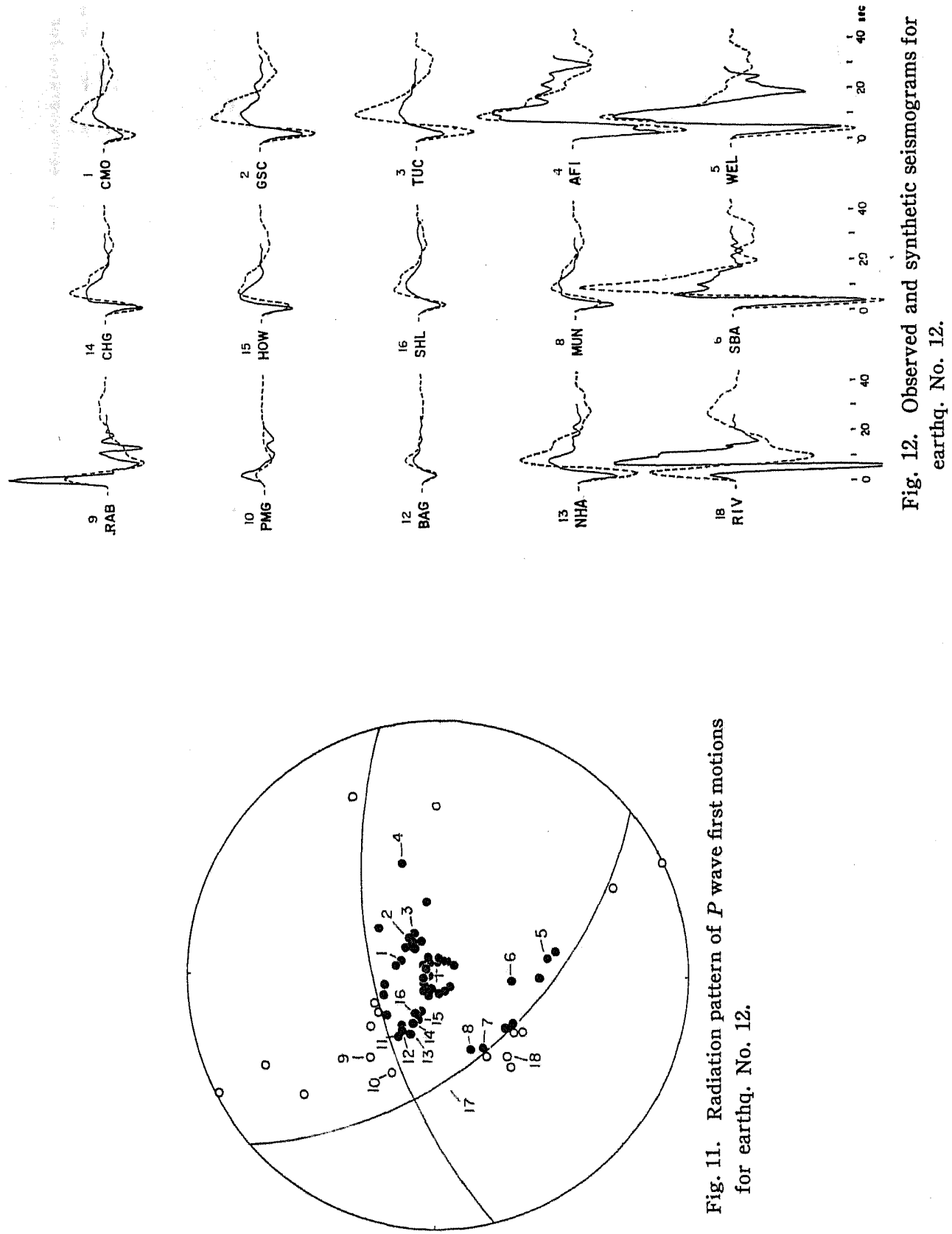

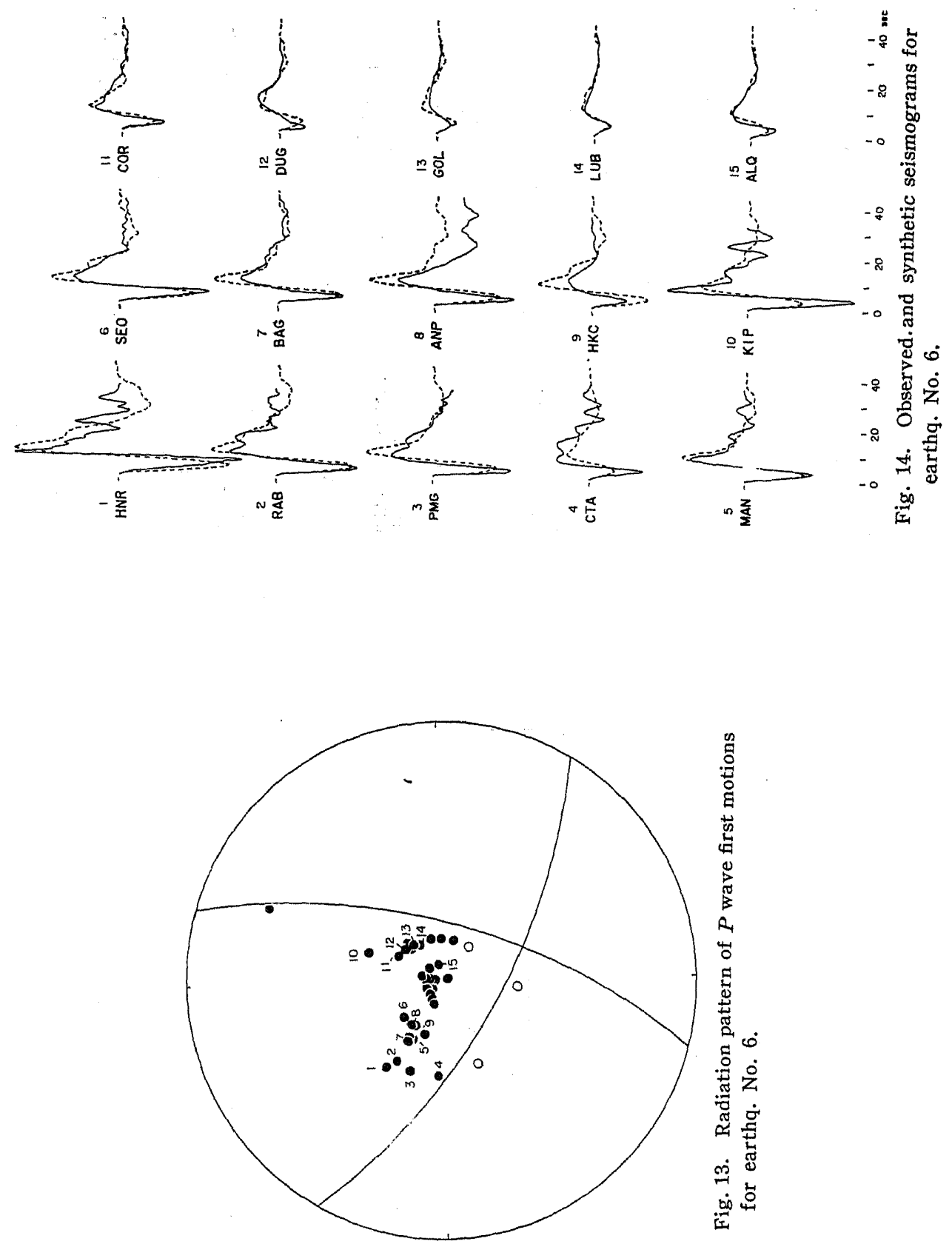

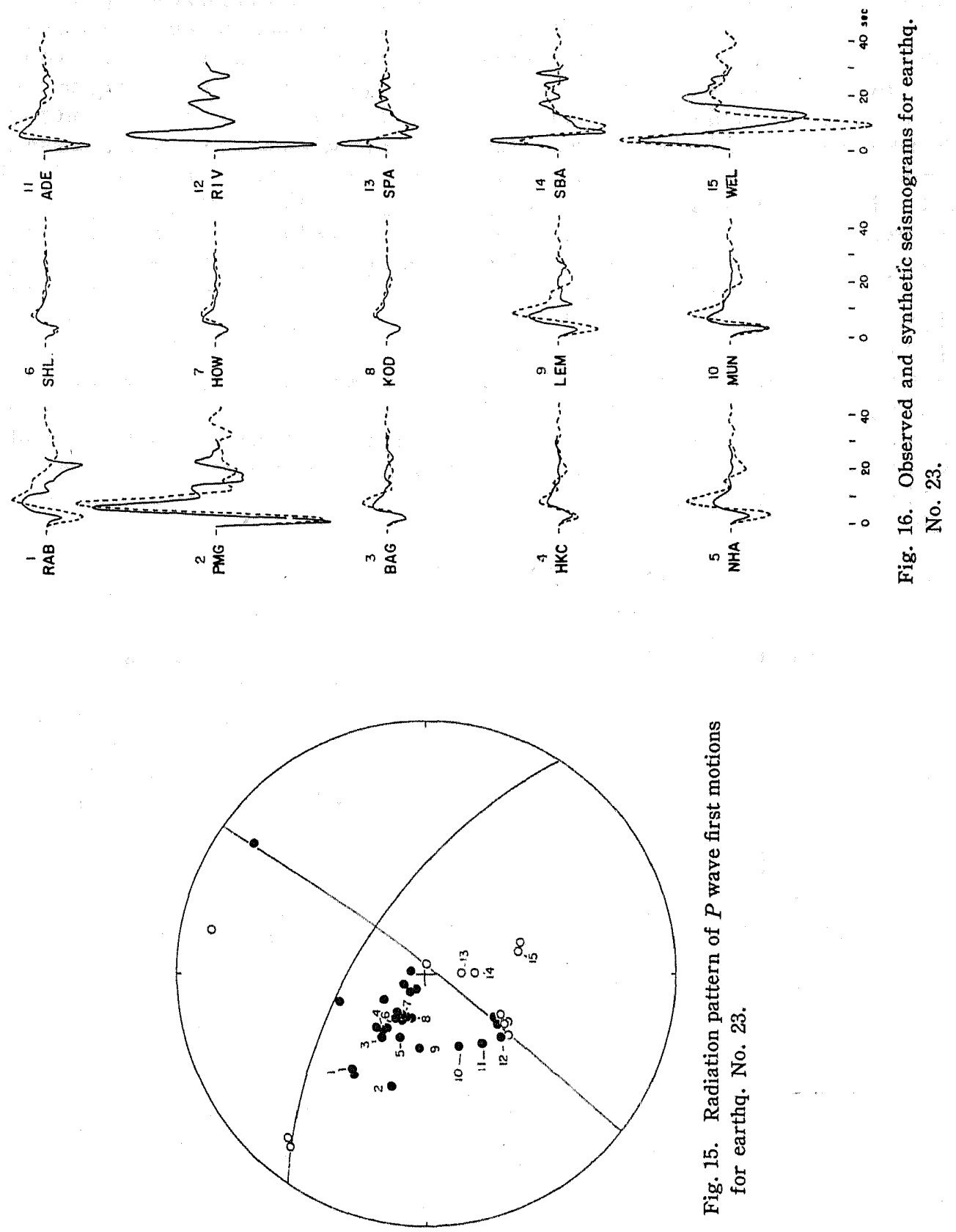
not great enough to produce such a pulse, as has been demonstrated in Fig. 2. The presence of the 'phase' with small second peaks suggests the possibility that the source time function would have a double-step form or the strain energy stored might have been released by double shocks.

Fig. 11 gives the fault-plane solution for earthquake No. 12, and the observed and synthesized seismograms are compared in Fig. 12. There appears again to be a fairly close agreement in the waveforms between the observation and theory except for a few stations. Such a phase-like event as seen in earthquake No. 15 cannot be clearly identified except for $R A B$, and the small second peak appears only for SBA. The most conspicuous discrepancy between the two waveforms comes from RIV, and there is similar situation for CTA (not shown here). The two stations are situated near a nodal plane striking in the NW-SE direction and record a small first motion of compression followed by a large dilatation. This appears to suggest that the source movement might have occurred at two stages, but there are no corresponding indications at the other stations. The question of the source mechanism is left unanswered.

In Figs. 13 and 14 are given the radiation pattern of $P$ waves and the observed and synthetic seismograms for earthquake No. 6 . Agreement in the waveforms is the closest among the four earthquakes investigated. As mentioned earlier, however, even closer agreement can be obtained for $\tau=2 \sim 3 \mathrm{sec}$ in point-source models rather than the case $\tau=0$ shown here.

Fig. 15 shows the fault-plane solution for earthquake No. 23 (superposed by some data from another shock), and Fig. 16 presents a comparison between the both kinds of seismograms. It appears that the observed records generally show the waveform as expected from theory, except for a few stations. We

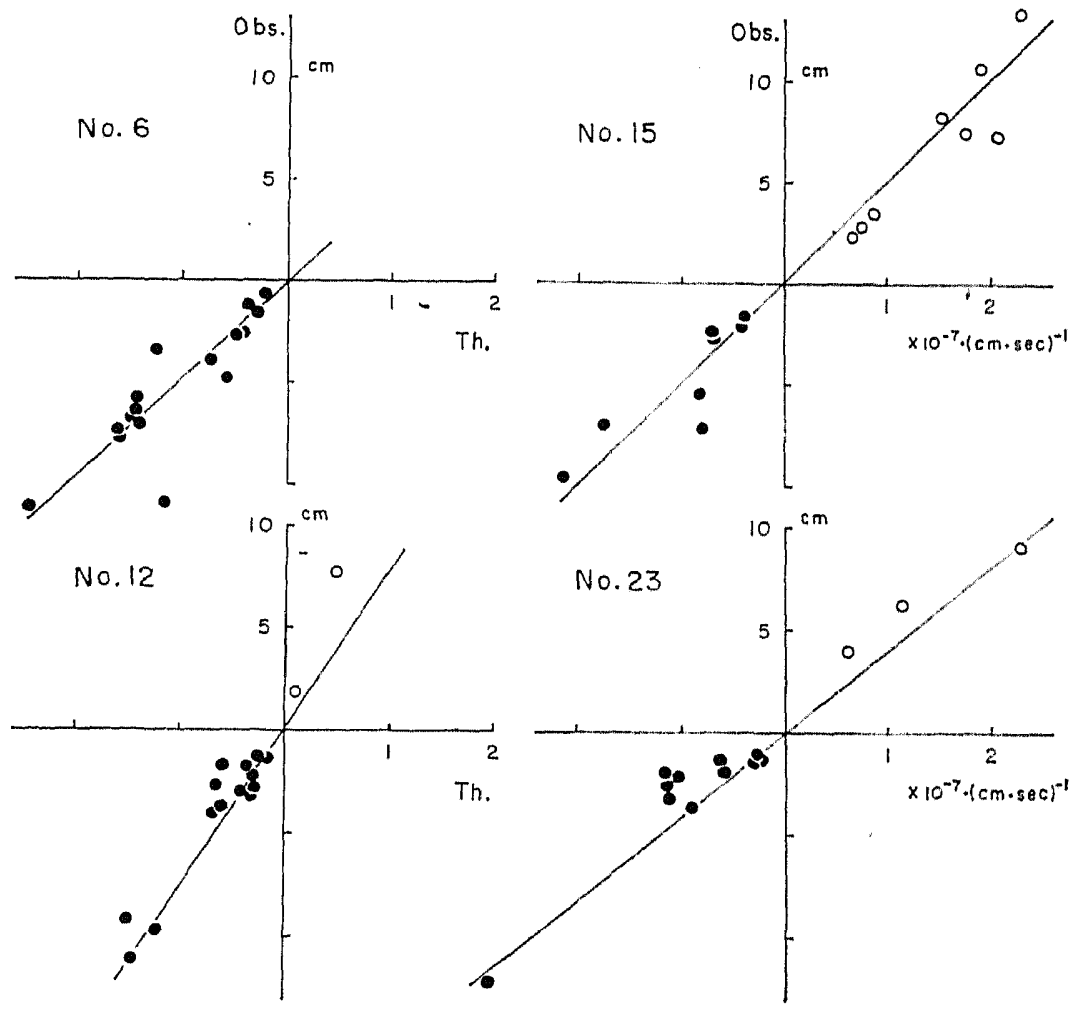

Fig. 17. Relation between the double amplitudes of the observed and synthetic seismograms. 
Table 4. Estimated source parameters.

\begin{tabular}{|c|c|c|c|c|c|c|c|c|}
\hline $\begin{array}{c}\text { Shock } \\
\text { No. }\end{array}$ & $\begin{array}{c}D L W \\
\times 10^{14} \mathrm{~cm}^{3}\end{array}$ & $\begin{array}{c}M_{0} \\
\times 10^{26} \text { dyne } \cdot \mathrm{cm}\end{array}$ & $\begin{array}{c}\sigma \\
\text { bar }\end{array}$ & $\begin{array}{l}\varepsilon \\
\times 10^{-4}\end{array}$ & $\begin{array}{c}E_{0} \\
\times 10^{22} \text { ergs }\end{array}$ & $\begin{array}{c}E_{s} \\
\times 10^{21} \text { ergs }\end{array}$ & $c$ & $\begin{array}{c}\bar{\sigma} c \\
\text { bar }\end{array}$ \\
\hline 15 & 7.9 & 5.3 & $>170$ & $>2.6$ & $>6.9$ & 3.55 & $<0.052$ & 4.5 \\
\hline 12 & 12.3 & 8.6 & $>280$ & $>4.0$ & $>17.0$ & 0.89 & $<0.005$ & 0.6 \\
\hline 6 & 7.6 & 5.4 & $>180$ & $>2.5$ & $>6.7$ & 3.55 & $<0.053$ & 4.7 \\
\hline 23 & 6.5 & 4.7 & $>160$ & $>2.2$ & $>5.1$ & 0.63 & $<0.013$ & 1.0 \\
\hline
\end{tabular}

notice, however, that the apparent period of the first one cycle at WEL is appreciably longer than that of the theoretical waveform, and that the record at RIV has a large amplitude in spite of its location near a nodal plane. These exceptions cannot be explained at this time.

It is to be again noted here that general features of the recorded waveforms for all the four earthquakes agree well with the synthetic seismograms from a point source. Fig. 17 gives the quantitative relation between the maximum double amplitude in the first one cycle of the observed records (in $\mathrm{cm}$ ) and that of the synthetic seismograms for the four earthquakes. The open and solid circles indicate compression and dilatation respectively. The relation may be represented by a straight line with a good approximation, suggesting that there would not be appreciable waveform distortion due to a propagating fault. The slope of the straight line yields the following quantity, from eq. (20) if the source of these earthquakes is explained by slip dislocation,

$$
\frac{|f(t)|_{\max }}{\left|f_{0}(t)\right|_{\max }}=\frac{D L W}{2 \pi a}\left(\frac{b}{a}\right)^{2}=\frac{M_{0}}{2 \pi \rho a^{3}}
$$

where $M_{0}=\mu D L W . \quad D L W$ or the seismic moment $M_{0}$ may be determined by least squares from the slope if the propagation velocities are known. It is noticed that the slope for earthquake No. 12 is significantly steeper than that for the other earthquakes, which gives a large moment, although its magnitude is of an order comparable with the others. The determined values of $D L W$ and $M_{0}$ are tabulated in Table 4 , where the rigidity was taken to be $6 \sim 7 \times 10^{11} \mathrm{dyne} / \mathrm{cm}^{2}$ at depths between 100 and $200 \mathrm{~km}$.

\section{§7. Discussion}

(1) We have so far discussed slip dislocation sources in the foregoing sections, since they may be regarded as likely models for the double-couple type mechanism. On the other hand, Evison (1967) claimed, after reinvestigating a large number of the polarity of $P$ wave first motions from 68 shallow to deep earthquakes over the world, that a majority of the earthquakes showed a radiation pattern with predominancy of either compression or dilatation over the other, and that this predominancy was reversed at depths around $200 \mathrm{~km}$ in the upper mantle. He suggested a source mechanism attributable to a sudden volume change due to polymorphic phase transitions. The volume change of material could be interpreted in terms of dislocations by a combination of positive and negative normal discontinuities (MARUYaMa, 1963), which would yield a radiation pattern of the cone-type or with possible predominancy of either compression or dilatation. This is inconsistent with the present case. However, his hypothesis cannot totally be rule out, since it has been shown from a different standpoint (RANDALL, 1966) that sudden phase transitions in the earth's material involving the change of source shape and density would produce a first motion pattern similar to the doublecouple type.

(2) Next, we shall discuss the possibility of extracting the source information in the frequency domain. In Fig 18, some examples of the source amplitude and phase spectra of $P$ waves from earthquake No. 15 are reproduced from the results of Mrkumo and OTsuka (1968), which have been obtained by compensating the effects of the earth-recording system (Ben-Menahem et al., 1965). 

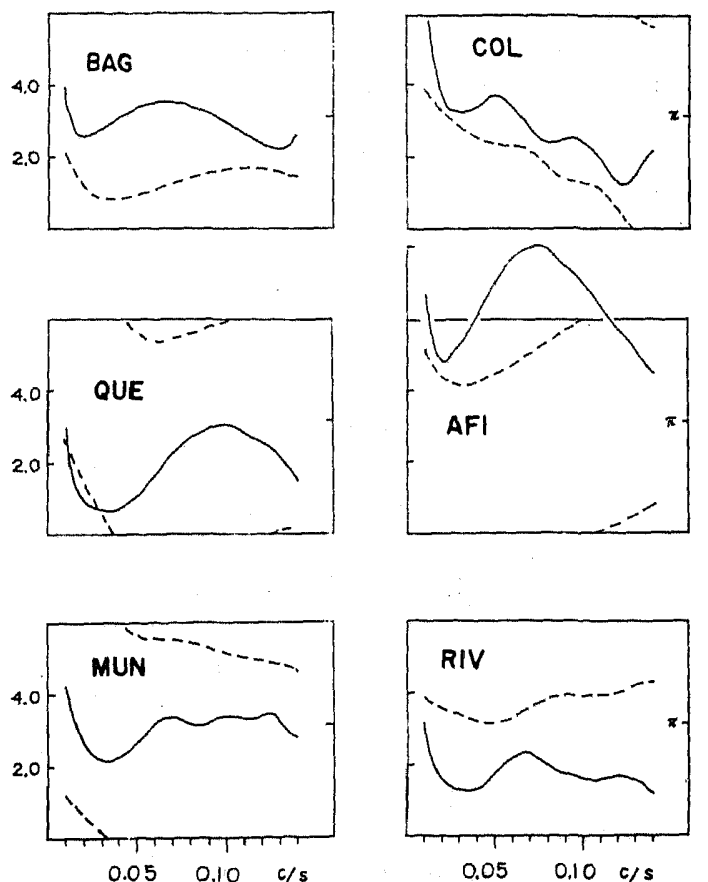

Fig. 18. Examples of source amplitude and phase spectra derived from observed records in earthq. No. 15.

The source amplitude spectra at the six stations do not show remarkable similarity. Although the spectra involve effects of the time dependence of dislocation and the source finiteness, as is clear from the relation $F(\omega)$ / $H(\omega)=\dot{U}(\omega) \cdot S(\omega)$, the former should yield the frequency dependence common to all the stations. However, the dissimilarity cannot be attributed directly to the source circumference, since the spectra in the frequency range shown here are likely to be contaminated by the presence of later phases and noise, the truncation of signal tail, or incorrect setting of a reference line on the records. Possible differences in $S(\omega)$ should appear at higher frequencies, if the source dimensions is of an order of $20 \mathrm{~km}$. For frequencies higher than $0.10 \mathrm{c} / \mathrm{s}$, however, minute structure in the upper crust gives serious effects on the spectra. It does not appear, therefore, that reliable information on the source parameters including the source moment can be derived from the amplitude spectra of $P$ waves, although some studies (Davis and Sмith, 1968; KHATtrI, 1969) have been made along this line.

Fig. 19 illustrates the phase spectra for the four earthquakes mentioned, where the left end of the spectrum $(0.01 \mathrm{c} / \mathrm{s})$ is plotted on the corresponding epicentral distance. Although it has been stated by KisнIмото (1964) that there was some difference in the slope of phase spectrum of $P$ waves between shallow earthquakes and intermediate and deep-focus shocks, the present results indicate that the slope varies with the location of recording stations with respect to the source even in a single earthquake. This may be understood from the fact that the source phase is related to the time function, source dimension, orientation of the slip plane and so forth, as is clear from $\varphi(\omega)=\varphi \dot{v}(\omega)+\varphi_{s}(\omega)$ and $\varphi_{s}(\omega)=$ $\omega\left(T_{L}+T_{W}\right)$ in case of unilateral faulting. The spectra have been compensated for the earthrecording system, but not for the arrival time delay. For more exact treatment, the initial phase would have to be derived from the standpoint of normal modes in a spherical earth (BRUNE, 1964). Once this correction was made, the difference in the spectra between any two stations in the case of unilateral faulting will be $\varphi_{j}(\omega)-\varphi_{k}(\omega)=\omega\left[\left(T_{L_{j}}-T_{L_{k}}\right)+\right.$ $\left.\left(T_{W_{j}}-T_{W_{k}}\right)\right]$. When the phases change monotonously with frequency, the difference in the slopes of the spectrum may be written

$$
\frac{d \varphi_{j}(\omega)}{d \omega}-\frac{d \varphi_{k}(\omega)}{d \omega}=-\frac{L}{2 a}\left(\alpha_{2 j}-\alpha_{2 k}\right)+\frac{W}{2 a}\left(\alpha_{3 j}-\alpha_{3 k}\right) \text {. }
$$

This relation suggests the possibility that $L / 2 a$ and $W / 2 a$ and hence the source dimensions $L$ and $W$ could be estimated by least squares from the slopes at more than three stations. Further consideration, however, will be needed for the procedure of determining the initial source phase before the application of this technique.

(3) A comparison between the observed records and synthetic seismograms from slipdislocation models has shown that the fault length would not exceed $20 \mathrm{~km}$ if a fracture velocity is around $3.5 \mathrm{~km} / \mathrm{sec}$. The fault width cannot be estimated, but this is expected to be smaller than the length. The conditions that $L<20 \mathrm{~km}$ and $W<20 \mathrm{~km}$, together with 


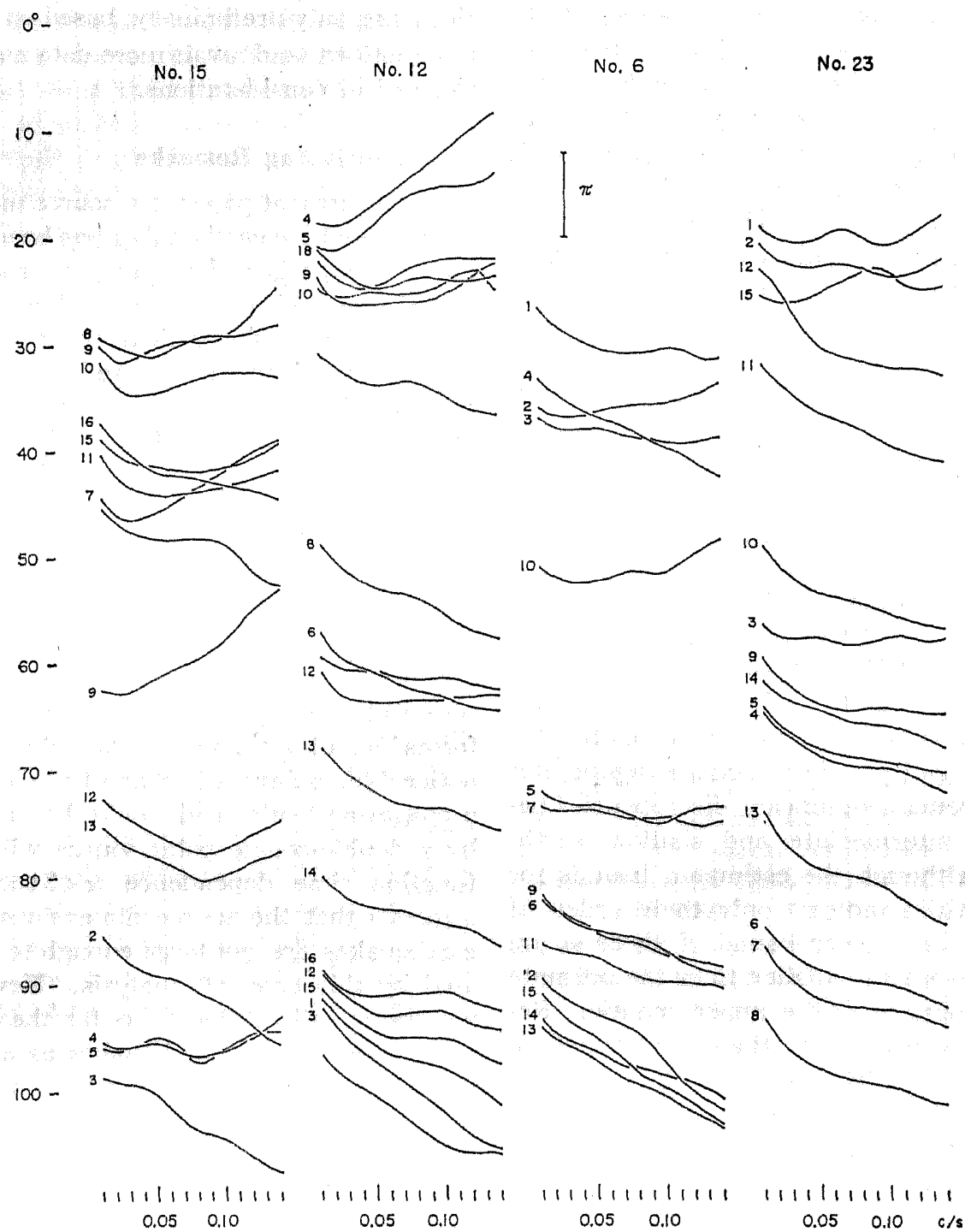

Fig. 19. Equalized phase spectra for four earthquakes.

the determined source moment, place a lower bound for the amount of dislocation, which is found to be $D>2 m$ for earthquakes Nos. 15,6 and 23 and $D>3 m$ for No. 12 .

The lower bounds of the stress drop at the source and hence the change in the strain, and of the strain energy released may be estimated from the above conditions with some assumptions. If the source could be approximated by a Starr fracture as has been assumed by AkI (1966), the stress drop and the corresponding shear strain will be $\sigma=$ $(16 / 3 \pi)(\mu \bar{D} / W)$ and $\varepsilon=\sigma / \mu$. Although this assumption might not always be valid for the present case, in view of its limited applicability to the edge dislocations, the use of the relation would give estimates for the order of stress-strain prior to earthquakes. The strain energy released $E_{0}$ by a slip dislocation is by definition equal to the work done during the movement and can be written as $E_{0}=\bar{\sigma} \bar{D} A=\bar{\sigma} M_{0} / \mu=M_{0} \bar{\varepsilon}$ (BRUNE, 1968), where $\bar{\sigma}$ 
is the average acting stress (average of the initial and final stresses) and $A$ is the area of a fault plane. On the other hand, the energy radiated by seismic waves $E_{s}$ may be evaluated from the earthquake magnitude $M$ following the well-known Gutenberg-Richter relation: $\log _{10} E_{s}=11.8+1.5 M$. The efficiency of conversion to seismic wave energy $c$ may be defined by $c=E_{s} / E_{0}$, and its upper bound will be inferred from the lower bound of $E_{0}$. $\bar{\sigma} c$, the lower bound of average stress, can also be evaluated from the seismic moment without any assumptions on source parameters. All the estimated values including the source moment are summarized in Table 4.

If we compare the seismic moment determined for the four intermediate earthquakes with that of shallow earthquakes with nearly the same magnitude (BRUNE, 1968; WYss and BRUNe, 1968), the present results are found to be larger by a factor of nearly 10 . A part of this reason may be accounted for by larger rigidity at intermediate depths, but there still remain significant discrepancies between the intermediate and shallow earthquakes. Although the estimated bounds for other quantities indicate only their order of magnitude, the lower bound of shear strain appears reasonably smaller than the ultimate strain appropriate to the upper mantle. Remarkable features of these intermediate earthquakes are high stress drop and very low seismic efficiency. The former may be related to the strength of material in the upper mantle, and/or the properties of fracture, which could be different from those in the shallow crust. On the other hand, the apparent low efficiency might be due to an underestimate of seismic wave energy, since the maximum amplitude is measured from body waves in intermediate earthquakes, but not from surface waves which are well excited and used to determine the magnitude in the case of shallow earthquakes. If this is not the case, the low efficiency might be associated with highly attenuative properties of the upper mantle as characterized by the existence of a low $Q$ layer, or with inherent nature of fractures there. These interpreta- tions are only preliminary, based on tentative assumptions, and await more data and further theoretical considerations.

\section{§ 8. Concluding Remarks}

In the present paper, the source mechanism of intermediate earthquakes has been discussed in comparison between the recorded $P$ waveforms and the corresponding synthetic seismograms. Theoretical waveforms have been synthesized on the basis of dislocation models with various source parameters, taking into account the effects of propagation and instrument. It was made clear that the synthesized waveforms are rather sensitive to variations in some of the source parameters such as the fauit length, fracture velocity and time constant, but are primarily controlled by the seismograph characteristics, and not greatly affected by the crustal structure and attenuation. The observed $P$ waveforms including the amplitude did not indicate noticeable, azimuthal characteristics due to propagating fault, and could be interpreted by a double-couple point source with a ramp function time dependence $(\tau<3 \mathrm{sec})$. This suggests that the source dimensions of these earthquakes are not large enough to be evaluated by this type of analysis. However, if we assume slip dislocations for the source of these intermediate earthquakes as a probable model yielding the double couple mechanism, the seismic source moment and possible bounds for some of the source parameters can be estimated.

In the present analysis, we have dealt only with the direct $P$ waves. The use of $S$ waves would be effective for the determination of the slip plane, the direction of fracture and the type of faulting (unilateral or bilateral), since the $S$ wave amplitude is more sensitive to the parameters than $P$ waves (Savage, 1966). It would be necessary, however, to examine whether the $S$ waveforms can also be explained by a dislocation model with the same parameters as for $P$ waves, since the predominant period of observed $S$ waves is used to be longer than that of $P$ waves. This is a problem left for the future investigation. 
To elucidate more clearly the physical processes at the source of intermediate earthquakes including the stress-strain drop and efficiency of seismic wave radiation and to establish their depth dependence in relation to the properties of the upper mantle, more earthquakes need to be analyzed.

\section{Acknowledgments}

I am grateful to Professor Tatsuo Usami of the Earthquake Research Institute, Professor Bruce A. Bolt, University of California, Berkeley, and Dr. Ryosuke Sato of the Geophysical Institute, University of Tokyo, for their suggestions and critical reading of the manuscript. I wish to thank Dr. Michio Otsuka, Mr. Kazuo Oike and Tsuneto Kurita for helpful discussions on the present problem. Dr. Karl Fuchs, of Universität Friederciana, Karlsruhe, Germany, kindly provided me the computed results of the source crustal transfer functions. My thanks are also due Mrs. Ritsuko Koizumi for assistance in the analysis and preparation of the manuscript.

Seismograms were supplied by the United States Coast and Geodetic Survey, and computations were made partly on a HITAC $5020 \mathrm{E}$ at the Computation Center, University of Tokyo, and partly on a FACOM 230-60 at the Computation Center, Kyoto University.

\section{References}

Aki, K., Generation and propagation of $G$ wave from the Niligata earthquake of June 16, 1964, Part 2. Estimation of earthquake moment, released energy and stress-strain drop from the $G$ wave spectrum, Bull. Earthq. Res. Inst., 44, 73-88, 1966.

Aki, K., Seismic displacements near a fault, $J$. Geophys. Res., 73, 5359-5377, 1968.

Ben-Menahem, A., Radiation of seismic body waves from a finite moving source in the earth, $J$, G6ophys. Res., 67, 345-350, 1962.

Ben-Menahem, A., S. W. Smith and T. L. Teng, A procedure for source studies from spectrums of long-period seismic body waves, Bull. Seism. Soc. Amer., 55, 203-235, 1965.

Bollinger, G. A., Determination of earthquake fault parameters from long-period $P$ waves, $J$. Geophys. Res., 73, 785-807, 1968.

Brune, J., Travel times, body waves and normal modes of the earth, Bull. Seism. Soc. Amer., 54, 2099-2127, 1964.

Brune, J., Seismic moment, seismicity, and rate of slip along major fault zones, J. Geophys. Res., 73, 777-784, 1968.

Burridge, R. and L. Knopoff, Body force equivalents for seismic dislocations, Bull. Seism. Soc. Amer., 54, 1875-1888, 1964.

Davis, J. B. and S. W. Smith, Source parameters of earthquakes, an discrimination between earthquakes and nuclear explosions, Bull. Seismi. Soc. Amer., 58, 1503-1517, 1968.

Evison, F.F., On the occurrence of volume change at the earthquake source, Bull. Seism. Soc. Amer., 57, 9-26, 1967.

Fuchs, K., The transfer function for $P$ waves for a system consisting of a point sourcè in a layered medium, Bull. Seism. Soc. Amer., 56, 75-108, 1966.

Haskell, N.A., Crustal reflection of plane $P$ snd $S V$ waves, J. Geophys. Res., 67, 4751-4767, 1962.

Haskell, N. A., Total energy and spectral density of elastic wave radiation from propagating fault, Bull. Seismo. Soc. Amer., 54, 1811-1841, 1964.

Hirasawa, T. and W. Stauder, On the seismic body waves from a finite moving source, Bull. Seism. Soc. Amer., 55, 237-262, 1965.

Honda, H., Earthquake mechanism and seismic waves, Geophys. Notes, Tokyo Univ., 15, Supplement, 1-97, 1962.

Isacks, B. L., L. R. Sykes and J. Oliver, Focal mechanism of deep and shallow earthquakes in the Tonga-Kermadec region and the tectonics of island arcs, Bull. Geol. Soc. Amer., 80, 1443-1470.

Ishimoto, M., Existence d'une source quadruple au foyer sismique d'apres l'étude de la distributions des mouvements initiaux des secousses sismiques, Bull. Earthq. Res. Inst., 10, 449- , 1932.

Khattri, K. N., Determination of earthquake fault plane, fault area, and rupture velocity from the spectra of long period $P$ waves and the amplitude of SH waves, Bull. Seism. Soc. Amer., 59, 615630, 1969.

Kishimoto, Y., Investigation on the origin mechanism of earthquakes by the Fourier analysis of seismic body waves, I., Bull. Disaster Prevention. Res. Inst., Kyoto Univ., 67, 1-37, 1964.

Knopoff, L. and F. Gilbert, Radiation from a strikeslip fault, Bull. Seism. Soc. Amer., 49, 163-178, 1959.

Knopoff, L. and F. Gilbert, First motions from seismic sources, Bull. Seism. Soc. Amer., 50, 117-134, 1960.

Maruyama, T., On the force equivalents of dyna- 
mical elastic dislocations with reference to the earthquake mechanism, Bull. Earthq. Res. Inst., 41, 467-486, 1963.

McConnell, R. K., R.N. Gupta and J.T. Wilson, Compilation of deep crustal seismic refraction profile, Rev. Geophys., 4, 41-55, 1966.

Mikumo, T. and T. Kurita, $Q$ distribution for long-

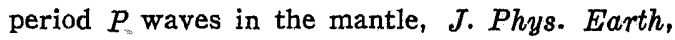
16, 11-29, 1968.

Mikumo, T. and M. Otsuka, Seismic source function of intermediate and deep earthquakes, read at the annual meeting of Seismological Society of Japan, 1968.

Mino, K., T. Onoguchi and T. Mikumo, Focal mechanism of earthquakes on island arcs in the southwest Pacific region, Bull. Disaster Prevention Res. Inst., Kyoto Univ., 18, 78-96, 1968.

Randall, M. J., Seismic radiation from a sudden phase transition, J. Geophys. Res., 71, 5297-5302, 1966.

Savage, J. C., The effect of rupture velocity upon seismic first motions, Bull. Seism. Soc. Amer.,
55, 263-275, 1965.

Savage, J.C., Radiation from a realistic model of faulting, Bull. Seism. Soc. Amer., 56, 577-592, 1966.

Stekettee, J. A., Some geophysical applications of the elasticity theory of dislocations, Can. $J$. Phys., 36, 1168-1198, 1958.

Teng, T. L. and A. Ben-Menahem, Mechanism of deep earthquakes from spectrums of isolated body-wave signals, 1. Banda Sea earthquake of March 21, 1964, J. Geophys. Res., 70, 5157-5170, 1965.

Usami, T., Y. Satô, M. Landisman and T. Odaka, Theoretical seismograms of spheroidal type on the surface of a gravitating elastic sphere, III, Case of a homogeneous mantle with a liquid core, Bull. Earthq. Res. Inst., 46, 791-819, 1968.

Wyss, M. and J. Brune, Seismic moment, stress, and source dimensions from earthquakes in the California-Nevada region, $J$. Geophys. Res., 73, 4681-4694, 1968.

(Received August 20, 1969) 